\title{
Effects of Sea-Salt Aerosols on Precipitation in Simulations of Shallow Cumulus
}

\author{
YEFIM L. KOGAN \\ Cooperative Institute for Mesoscale Meteorological Studies, University of Oklahoma, Norman, Oklahoma, \\ and Scripps Institution of Oceanography, University of California, San Diego, San Diego, California \\ DAVID B. MECHEM \\ Atmospheric Science Program, Department of Geography, University of Kansas, Lawrence, Kansas
}

KITYAN CHOI

Atmospheric and Oceanic Sciences Program, Princeton University, Princeton, New Jersey

(Manuscript received 18 January 2011, in final form 23 August 2011)

\begin{abstract}
A suite of large-eddy simulations with size-resolving microphysical processes was performed in order to assess effects of sea-salt aerosols on precipitation process in trade cumulus. Simulations based on observations from the Rain in Cumulus over the Ocean (RICO) field campaign explored the effects of adding sea-salt nuclei in different size ranges by following the evolution of 369 cloud cells over the 24-h simulation period. The addition of large (small) sea-salt nuclei tends to accelerate (suppress) precipitation formation; however, in marine environments the sea-salt spectra always include a combination of both small (film) and large (jet) nuclei. When realistic sea-salt spectra are specified as a function of surface wind, the effect of the larger nuclei to enhance the precipitation predominates, and accumulated precipitation increases with wind speed. This effect, however, is strongly influenced by the choice of background CCN spectrum. Adding the same sea-salt specification to an environment with a higher background aerosol load results in a decrease in accumulated precipitation with increasing surface wind speed.

Results also suggest that the slope of the relationship between vertical velocity $W$ and the concentration of embryonic precipitation particles at cloud base $N_{r}$ may indicate the role of sea-salt nuclei. A negative slope $\left(N_{r}\right.$ decreasing with increasing $\left.W\right)$ points to the predominance of small sea-salt nuclei, in which larger updrafts activate a greater number of smaller cloud drops with smaller coalescence efficiencies, resulting in fewer embryonic rain drops. A positive slope, on the other hand, indicates the presence of large sea-salt nuclei, which are the source of embryonic rain drops.
\end{abstract}

\section{Introduction}

Shallow trade wind cumuli are ubiquitous over much of the subtropical and tropical oceans and play an important role in the energy balance of the climate system. Estimates of future climate change scenarios in global climate models (GCMs) are particularly sensitive to how these types of low clouds are represented (Bony and Dufresne 2005; Wyant et al. 2006; Medeiros et al. 2008). Shallow cumulus clouds over the subtropical and tropical

Corresponding author address: Yefim Kogan, Cooperative Institute for Mesoscale Meteorological Studies, University of Oklahoma, 120 David L. Boren Blvd., Suite 2100, Norman, OK 73072-7304.

E-mail: ykogan@ou.edu oceans serve to cool and moisten the lower atmosphere. This cooling and moistening not only maintains the lower tropospheric thermodynamic structure against subsidence but also plays a role in preconditioning the tropical atmosphere for deep convection (Riehl et al. 1951; Siebesma 1998).

Theoretical models of the trade cumulus boundary layer (BL) [see Betts (1997), Siebesma (1998), and Stevens (2005) for nice summaries] have assumed, mainly for reasons of simplicity, that these clouds do not precipitate. However, as Rauber et al. (2007) note, precipitation frequently accompanies shallow cumulus clouds. A recent field campaign [Rain in Cumulus over the Ocean (RICO)], conducted during the boreal winter of 2004/05 in the Lesser Antilles region, was undertaken in order to characterize and understand the properties of trade wind 
cumulus (Rauber et al. 2007). Of particular interest was to assess the prevalence of precipitation and its influence on the evolution of cloud and boundary layer properties.

The contribution of shallow boundary layer clouds to total precipitation is not well understood. Using products from the Tropical Rainfall Measuring Mission (TRMM), Schumacher and Houze (2003) found large areas of precipitation they categorized as "shallow, isolated pixels," which we take to roughly correspond to boundary layer cloud. Employing similar TRMM products, Short and Nakamura (2000) concluded that shallow precipitation is responsible for approximately $20 \%$ of oceanic precipitation. Precipitation rate estimates during RICO range from a low of $0.7-1.2 \mathrm{~mm}^{-1}$ day $^{-1}$ (Nuijens et al. 2009) to a high of $2.37 \mathrm{~mm}^{\text {day }}{ }^{-1}$ (Snodgrass et al. 2009). Precipitation is an important contribution to the moisture budget, constituting approximately $1 / 3$ of the surface moisture flux in the Nuijens et al. estimate.

For shallow marine clouds, the trade inversion limits cloud growth to well below the $0^{\circ} \mathrm{C}$ isotherm (in RICO, maximum cloud-top height corresponded to $\sim 4 \mathrm{~km}$; Rauber et al. 2007; Snodgrass et al. 2009). For this reason, trade cumuli represent an ideal laboratory for studying the warm rain precipitation process. Despite significant efforts, the warm rain process is not fully understood. One of the most glaring points of uncertainty is the coalescence bottleneck-that is, the formation of appreciable precipitation-sized droplets that can fall and efficiently collect smaller cloud drops. Two prevailing but not mutually exclusive mechanisms have been proposed to explain the formation of precipitation embryos. Marine environments are typically characterized by small concentrations of cloud condensation nuclei $(\mathrm{CCN})$, which lead to small droplet concentrations. Compared to cloud droplets nucleated on a large number of $\mathrm{CCN}$ in a continental air mass, the relatively small number of large droplets in the marine environment will rather quickly reach the size needed for efficient growth by coalescence. Thus, in circumstances of very clean air masses or high liquid water content, submicron-size $\mathrm{CCN}$ are sufficient to lead to the initiation of precipitation (Johnson 1982; Cooper et al. 1997; Feingold et al. 1999).

Giant $\mathrm{CCN}(\mathrm{GCCN})^{1}$ have been proposed as another mechanism to explain the formation of drizzle embryos. GCCN deliquesce into droplets many times their dry size and quickly after activation may be of sufficient size

\footnotetext{
${ }^{1}$ Depending on their dry radius $r_{d}$, aerosols are usually classified as large $\left(0.1<r_{d}<1.0 \mu \mathrm{m}\right)$, giant $\left(1.0<r_{d}<10.0 \mu \mathrm{m}\right)$, or supergiant $\left(r_{d}>10.0 \mu \mathrm{m}\right)$. There is no unanimity in this classification, however, as these ranges are often also defined with respect to nucleus diameter.
}

to serve as drizzle nuclei (Johnson 1982). Both observational (Illingworth 1988; Lasher-Trapp et al. 2001) and modeling studies (Johnson 1982; Laird et al. 2000; Lasher-Trapp et al. 2001) support the idea that the GCCN mechanism may act in some cases to initiate precipitation.

Perhaps the most comprehensive investigation of the role of $\mathrm{CCN}$ particles on precipitation formation was conducted by Cooper et al. (1997), who evaluated the results of hygroscopic seeding of warm clouds by flares. Using accurate parcel-model calculations, Cooper et al. investigated in detail the role of $\mathrm{CCN}$ of different sizes and concentrations and considered the combined effect of the full spectrum of $\mathrm{CCN}$ particles. Their results confirmed the beneficial effect on precipitation initiation of very large nuclei but also demonstrated that the concentration of accumulation-mode particles may influence coalescence rates and precipitation efficiency.

The role of accumulation-mode particles may be especially important in clean maritime environments (Johnson 1982; Feingold et al. 1999). This conclusion was confirmed in comparisons of maritime and continental cumulus clouds in the vicinity of the eastern Florida coast [the Small Cumulus Microphysics Study (SCMS)]. Results from SCMS indicate that that the differences in precipitation between clouds are most strongly modulated by variability in submicron, rather than giant, $\mathrm{CCN}$ (Hudson and Yum 2001; Göke et al. 2007). On the other hand, observations from the very same field campaign indicate that GCCN can play a role in initiating coalescence (Blyth et al. 2003).

Interpretations of the RICO observations are similarly mixed. Gerber et al. (2008) emphasized the important role of entrainment in RICO shallow cumulus and found that under subadiabatic conditions the coalescence of smaller drops with those formed on ultragiant CCN was essential in explaining the development of the drop size distribution tail in flight RF12, which was characterized by a greater concentration of submicron $\mathrm{CCN}$ relative to the other RICO cases. Lowenstein et al. (2010) argued that the drop size distribution $1 \mathrm{~km}$ above cloud base was consistent with condensational growth of activated submicron, large, giant, and ultragiant CCN. The closed parcel model employed in their study, however, did not account for entrainment. On the other hand, radar (Knight et al. 2008) and in situ observations (Hudson and Mishra 2007; Hudson et al. 2009) consistently demonstrated that GCCN did not play a role in initiating coalescence during RICO, a finding confirmed by parcel-model calculations of Reiche and Lasher-Trapp (2010). Select simulations employing size-resolving (bin) microphysics were able to obtain substantial precipitation rates $\left(\sim 1 \mathrm{~mm} \mathrm{day}^{-1}\right)$ for RICO clouds without including 
GCCN in the aerosol spectrum (Jiang et al. 2009; van Zanten et al. 2011). Nuijens et al. (2009) went a step further and argued that the RICO observations provide little evidence for even submicron $\mathrm{CCN}$ acting as a controlling factor for precipitation, which instead is strongly modulated by cloud depth (Stevens and Seifert 2008).

In summary, despite the well-established effects of GCCN on cloud precipitation in many modeling and observational studies, their role in nature under specific atmospheric conditions remains ambiguous and subject to scientific debate. One important aspect of the uncertainty may be due to the competing effects of small versus large cloud drops, and the presence or absence of embryonic precipitation drops formed on giant $\mathrm{CCN}$. In marine environments in particular, the concentration of large (jet) and small (film) CCN are not independent, as they are produced simultaneously by breaking waves driven by surface winds (e.g., O'Dowd et al. 1997). The goal of this study, therefore, is to investigate the combined effects of sea-salt aerosols considered over the entire size spectrum under conditions characteristic of shallow trade wind cumulus, such as those observed during the RICO project.

Additional motivation for our investigation was provided in the study by Colón-Robles et al. (2006), who analyzed in situ microphysical probe observations from the National Center for Atmospheric Research (NCAR) C-130 flown during RICO. They found that 1) stronger low-level (100-m altitude) winds were associated with stronger updrafts and 2) these more robust updrafts were accompanied by a larger number of activated cloud droplets just above cloud base, smaller mean droplet size, and a smaller number of large drops (Fig. 1). From the view of the GCCN mechanism these results seem paradoxical, given the fact that the GCCN flux from the surface is proportional to surface wind speed (O'Dowd et al. 1997). However, increasing surface wind speed is also accompanied by an increase in updraft strength, which via increasing supersaturation has the ability to activate more $\mathrm{CCN}$. Thus, competing effects are present, with stronger winds leading to activation of a greater number of submicron CCN (which suppresses the warmrain process), but also to an increase in GCCN (which enhances the warm-rain process).

The work of Colón-Robles et al. (2006) suggests that the sensitivity of cloud base droplet size and concentration to wind (or updraft) strength may serve as a hint as to the efficacy of the GCCN mechanism. We employ this idea in formulating the goals of this study, which are 1) to assess the effects of the sea-salt aerosol produced by surface winds on the precipitation process in shallow cumulus clouds and 2) to evaluate the sensitivity of cloud-base drop size to updraft strength.

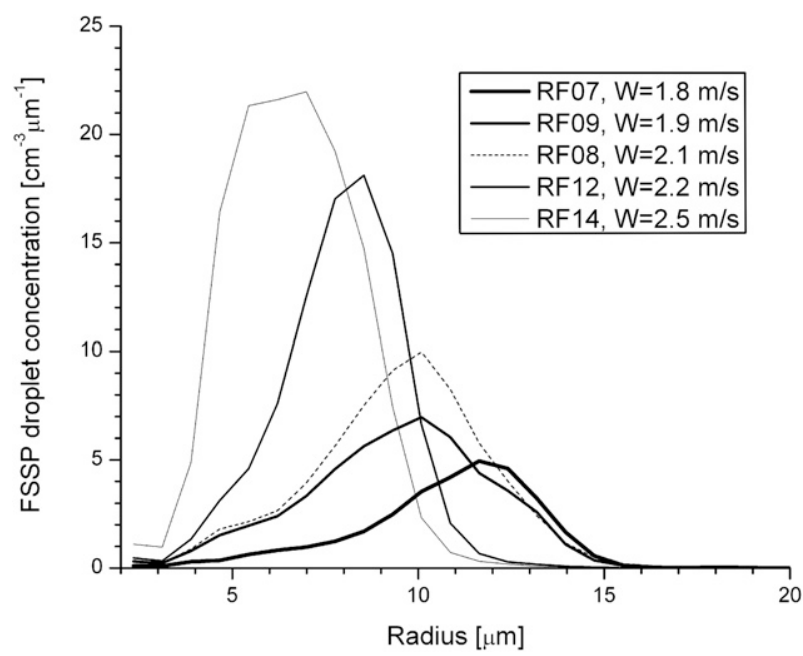

FIG. 1. Adapted from Fig. 4a of Colón-Robles et al. (2006). Vertical velocity values corresponding to each flight were obtained using their relationship $w=1.089+0.106 U$, where $U$ is the $100-\mathrm{m}$ altitude horizontal wind speed listed in their Fig. 4a. Stronger updrafts in RICO result in larger total droplet concentration but a smaller concentration of large drops.

In this study, we focus on isolating the microphysical response to differences in sea-salt nuclei arising from stronger surface winds. Cloud dynamical responses to increasing surface winds, caused for example by stronger surface fluxes, are neglected in our study, as are differences in large-scale meteorological conditions that likely accompany increases in surface winds. Our approach can be viewed as one branch of a factorial analysis (Stein and Alpert 1993; Dearden 2009), with the other components being the evaluation of dynamical effects of increasing surface winds, and a final simulation where both dynamical and aerosol factors are tested. Evaluating the interactions of all possible factors is far beyond the scope of our study, and the simplified experimental design is crucial in providing the ability to clearly isolate and interpret sensitivities of microphysical processes.

\section{Model}

The simulations employ the new version of the Cooperative Institute for Mesoscale Meteorological Studies (CIMMS) large-eddy simulation (LES) (Kogan et al. 1995; Khairoutdinov and Kogan 1999) called the System for Atmospheric Modeling-Explicit Microphysics (SAMEX). The dynamical core consists of the System for Atmospheric Modeling (SAM), developed by M. Khairoutdinov (Khairoutdinov and Randall 2003). SAM is based on nonhydrostatic anelastic dynamics and uses a monotonic, positive-definite advection scheme for scalars (Smolarkiewicz and Grabowski 1990). The subgrid-scale 
model is the turbulent kinetic energy (TKE)-based closure of Deardorff (1980). SAMEX has been extensively tested on marine stratocumulus [the Atlantic Stratocumulus Transition Experiment (ASTEX) case] and was employed in the latest Global Energy and Water Cycle Experiment (GEWEX) Cloud System Study (GCSS) model intercomparison of marine trade cumulus based on RICO observations (van Zanten et al. 2011). Results for the ASTEX and RICO cases compare favorably with the original CIMMS and community LES models. The current formulation of SAMEX uses 34 cloud-drop bins ranging in size from $1 \mu \mathrm{m}$ up to $2 \mathrm{~mm}$, and $19 \mathrm{CCN}$ bins with aerosol dry radius sizes ranging from 0.076 to $5.5 \mu \mathrm{m}$.

The CCN particles (considered of $\mathrm{NaCl}$ origin) in a specific size interval are activated as soon as the supersaturation exceeds the critical value determined by the Köhler equation. Actually, cloud condensation nuclei start growing long before they enter the cloud, even at supersaturations less than critical. Representing CCN deliquescence in the microphysical calculations is important in determining the initial value of the newly activated cloud drops.

For shallow cumulus clouds over the land, Ivanova et al. (1977) performed detailed calculations of the aerosol deliquescence (swelling) process in the subcloud layer. At zero supersaturation, nuclei with dry radius less than some threshold value $\left(r_{n}<r_{n}^{*}\right)$ will form solution drops of wet radius $r_{w}$ equal to the equilibrium size. For dry nuclei larger than this threshold value $\left(r_{n}>r_{n}^{*}\right)$, the wet radius of the solution droplet at zero supersaturation level will exceed $r_{n}$ by a factor of $k$, where $r_{n}^{*}$ and $k$ are functions of updraft velocity defined in Kogan (1991).

The calculations in Ivanova et al. (1977) are highly idealized. The "wet" radii of $\mathrm{CCN}$ at cloud base were determined by considering a simple Lagrangian air parcel model of a warm bubble rising from the surface at constant velocity. Dilution of the updraft properties via entrainment was neglected, and the time scale $\tau$ for $\mathrm{CCN}$ particle condensational growth in the subcloud layer was assumed to be $\tau=H / W$, where $H$ is the height of the cloud base and $W$ is the characteristic velocity of subcloud-layer updrafts. The trajectories of $\mathrm{CCN}$ particles in a turbulent boundary layer of a marine environment may be more complex and, consequently, their residence times may be larger than the estimates of Ivanova et al. Indeed, according to Lewis and Schwartz (2004), even relatively large aerosol particles reside in the marine boundary layer for many hours. Furthermore, the trajectory analysis in Kogan (2006) also suggests that air parcels in the marine boundary layer may cycle for hours before entering the cloud. These results indicate that the idealized calculations of Ivanova et al. may, in some cases, underestimate the wet radii.
For these more complex cases, Ivanova et al. (1977) suggested that a simpler parameterization with $k=$ const can be used for most modeling applications. In our simulations, nuclei with dry radii $r_{n}<0.058 \mu \mathrm{m}$ corresponded to $r_{w}$ set to equilibrium size at zero supersaturation. For larger particles, $r_{w}=k r_{n}$ with $k \sim 6.0$, resulting in wet sizes smaller than the zero supersaturation equilibrium value. This parameterization reflects the very short condensational growth time scale for small nuclei and the slower growth rates for larger particles. A rigorous physical justification of this particular value of $k$ is difficult, as it requires a complex analysis of the history of air parcels in the subcloud layer and Lagrangian calculations of condensational growth of dry CCN particles in turbulent flow. In our model, the value of $k$ was selected from sensitivity experiments based on ASTEX A209 flight data to best match the available observed drizzle parameters.

To indirectly assess the sensitivity of RICO simulation results to the choice of the value of $k$, or equivalently to the concentration of nuclei in the right tail of the spectrum $\left(r_{d}>0.129 \mu \mathrm{m}\right)$, we performed an additional experiment in which the concentration of large nuclei was decreased by a factor of 5 (experiment LN5; see Table 2), roughly mimicking a reduction of $k$ in this size range. The results of this simulation are described in the appendix and demonstrate that by the end of the simulation the accumulated surface precipitation was within a few percent of the benchmark experiment.

As shallow cumulus clouds in the marine environment continually grow and dissipate over long time periods, they regenerate $\mathrm{CCN}$ particles, which are then recycled into newly formed clouds. The process of $\mathrm{CCN}$ regeneration is therefore quite important, but a physically grounded formulation of this process requires the introduction of a two-dimensional distribution function that depends on parameters of the drop and its soluble fraction. In a multidimensional dynamical framework, this twodimensional distribution formulation is technically difficult and computationally expensive. Because we have a onedimensional drop size distribution that does not carry information on dissolved solute fraction, the process of regeneration has to be parameterized. As described in Khairoutdinov and Kogan (1999), the regenerated CCN spectra are restored to the initial shape after drop evaporation. A sensitivity study by Kogan et al. (1994) tested three different $\mathrm{CCN}$ regeneration spectra in simulations of a stratocumulus cloud layer. It was found that the particular choice of regenerated spectrum had substantially less effect on boundary layer cloud properties than the differences arising from neglecting $\mathrm{CCN}$ regeneration altogether.

The model horizontal and vertical grid spacings for the simulation were $100 \mathrm{~m}$ and $40 \mathrm{~m}$, respectively, with 
TABLE 1. Specification of numerical experiments: $U$ is surface wind; $N_{\mathrm{ccn}}$ is background CCN concentration; $N_{\mathrm{ss}}, N_{f}$, and $N_{j}$ are concentrations of total sea-salt CCN, and its film $\left(r_{d} \leq 0.82 \mu \mathrm{m}\right)$ and jet $\left(r_{d}>0.82 \mu \mathrm{m}\right)$ components, respectively.

\begin{tabular}{clccccc}
\hline \hline Run & Label & $\begin{array}{c}U \\
\left(\mathrm{~m} \mathrm{~s}^{-1}\right)\end{array}$ & $\begin{array}{c}N_{\mathrm{ccn}} \\
\left(\mathrm{cm}^{-3}\right)\end{array}$ & $\begin{array}{c}N_{\mathrm{ss}} \\
\left(\mathrm{cm}^{-3}\right)\end{array}$ & $\begin{array}{c}N_{f} \\
\left(\mathrm{~cm}^{-3}\right)\end{array}$ & $\begin{array}{c}N_{j} \\
\left(\mathrm{~cm}^{-3}\right)\end{array}$ \\
\hline 1 & STD & 12.0 & 104.4 & 0 & 0 & 0 \\
2 & TOT & 12.0 & 104.4 & 29.27 & 28.75 & 0.52 \\
3 & TOT17 & 17.0 & 104.4 & 82.1 & 81.3 & 0.80 \\
4 & hiTOT & 12.0 & 154.0 & 29.27 & 28.75 & 0.52 \\
5 & hiTOT17 & 17.0 & 154.0 & 82.1 & 81.3 & 0.80 \\
6 & FLM & 17.0 & 104.4 & 56.5 & 56.5 & 0.00 \\
7 & JET & 17.0 & 104.4 & 56.5 & 55.0 & 1.50 \\
8 & LN5 & 12.0 & 104.4 & 24.514 & 24.41 & 0.104 \\
\hline
\end{tabular}

a total of $128 \times 128 \times 100$ grid points $(12.8 \times 12.8 \times$ $4 \mathrm{~km}^{3}$ domain). The dynamical time step was $2 \mathrm{~s}$. The SAMEX model is computationally quite efficient: a 24-h RICO simulation takes approximately $10 \mathrm{~h}$ of wallclock time using 64 processors on the Linux computing cluster (2.0-GHz Intel Pentium4 Xeon E5405 quad-core "Harpertown" processors; two processors per node; Infiniband interconnect) at the University of Oklahoma (OU) Supercomputing Center for Education and Research (OSCER).

A threshold radius of $20.2 \mu \mathrm{m}$ was employed to delineate cloud-size droplets from precipitation-size drops (concentration denoted by $N_{r}$ ) and was chosen to match as closely as possible the cloud droplet measurements of Colón-Robles et al. (2006), which were based on a forward scattering spectrometer probe (FSSP/SPP-100) that had an upper size limit of $23 \mu \mathrm{m}$. The choice of a relatively small threshold captures in the $N_{r}$ calculation embryonic precipitation particles and therefore can directly assess the sensitivity of the precipitation process to fundamental aerosol parameters.

A mixing ratio threshold for liquid water of $Q_{l}>$ $0.001 \mathrm{~g} \mathrm{~kg}^{-1}$ was used to identify cloud boundaries. This threshold is an order of magnitude smaller (more sensitive) than the threshold specified in the RICO intercomparison (van Zanten et al. 2011), resulting in a slightly higher cloud fraction in our simulations.

\section{Experimental configuration and data description}

\section{a. Initial conditions and forcing}

The simulation configuration was based on that employed in the GCSS-RICO intercomparison (van Zanten et al. 2011). Initial profiles and simulation forcings corresponded to average conditions over the 3-week period from 16 December 2004 to 8 January 2005. Temperature tendency, moisture tendency, and subsidence
TABLE 2. Values of microphysical parameters: $r_{d}\left(r_{w}\right)$ is radius of dry (wet) $\mathrm{CCN}$ particle in bin $i$, and $k$ is a constant for specification of wet radius. Column STD contains cumulative distribution of background CCN particles; columns FLM-TOT17 contain cumulative distribution of additional sea-salt nuclei.

\begin{tabular}{|c|c|c|c|c|c|c|c|c|c|}
\hline$i$ & $\begin{array}{c}r_{d} \\
(\mu \mathrm{m})\end{array}$ & $\begin{array}{c}r_{w} \\
(\mu \mathrm{m})\end{array}$ & $k$ & STD & FLM & JET & TOT & TOT17 & LN5 \\
\hline 1 & 0.0076 & 0.0216 & 2.84 & 0.00 & 0 & 0 & 0.00 & 0.00 & 0.00 \\
\hline 2 & 0.012 & 0.0428 & 3.57 & 0.27 & 0 & 0 & 0.00 & 0.00 & 0.00 \\
\hline 3 & 0.0145 & 0.0568 & 3.92 & 0.77 & 0 & 0 & 0.00 & 0.00 & 0.00 \\
\hline 4 & 0.0158 & 0.0646 & 4.09 & 1.9 & 0 & 0 & 0.00 & 0.00 & 0.00 \\
\hline 5 & 0.0175 & 0.0753 & 4.30 & 3.6 & 0 & 0 & 0.00 & 0.00 & 0.00 \\
\hline 6 & 0.0186 & 0.0825 & 4.44 & 5.8 & 0 & 0 & 0.00 & 0.00 & 0.00 \\
\hline 7 & 0.0198 & 0.0906 & 4.58 & 9.6 & 0 & 0 & 0.12 & 0.35 & 0.12 \\
\hline 8 & 0.0212 & 0.1 & 4.72 & 16.1 & 4 & 0 & 0.45 & 1.3 & 0.45 \\
\hline 9 & 0.023 & 0.114 & 4.96 & 26.3 & 20 & 0 & 1.02 & 3.0 & 1.0 \\
\hline 10 & 0.0251 & 0.129 & 5.14 & 41.3 & 31 & 0 & 1.67 & 4.8 & 1.7 \\
\hline 11 & 0.0278 & 0.151 & 5.43 & 68.8 & 55 & 0 & 2.6 & 7.5 & 2.6 \\
\hline 12 & 0.0364 & 0.22 & 6.04 & 89.3 & 55.8 & 0 & 5.2 & 15.0 & 5.2 \\
\hline 13 & 0.0579 & 0.347 & 5.99 & 95.0 & 56.4 & 4 & 9.5 & 27.4 & 9.5 \\
\hline 14 & 0.129 & 0.774 & 6.00 & 102.3 & 56.5 & 20 & 21.0 & 60.8 & 21.0 \\
\hline 15 & 0.22 & 1.32 & 6.00 & 104.4 & 56.5 & 31 & 27.2 & 78.0 & 24.1 \\
\hline 16 & 0.82 & 4.92 & 6.00 & 104.4 & 56.5 & 55 & 28.75 & 81.3 & 24.41 \\
\hline 17 & 1.66 & 9.96 & 6.00 & 104.4 & 56.5 & 55.8 & 29.0 & 81.7 & 24.46 \\
\hline 18 & 3.5 & 20.1 & 5.74 & 104.4 & 56.5 & 56.4 & 29.23 & 82.0 & 24.506 \\
\hline 19 & 5.5 & 31 & 5.64 & 104.4 & 56.5 & 56.5 & 29.27 & 82.1 & 24.514 \\
\hline
\end{tabular}

rate constituted the forcing. For reasons of computational expense and consistency across all the different intercomparison participants, radiative forcing was not explicitly calculated but rather was incorporated into the temperature tendency. Surface fluxes were calculated using a standard bulk aerodynamic approach with a fixed sea surface temperature of $299.8 \mathrm{~K}$. The geostrophic horizontal wind components were specified as $u=-9.9 \mathrm{~m} \mathrm{~s}^{-1}$ and $v=-3.8 \mathrm{~m} \mathrm{~s}^{-1}$ and did not change with height or time. See van Zanten et al. (2011) for details regarding the simulation configuration.

\section{b. Specification of CCN spectra}

A series of eight experiments (see Tables 1 and 2 for specification) was performed in this study. The benchmark experiment (labeled STD) employed a background $\mathrm{CCN}$ distribution characteristic of a clean maritime environment and was specified to be homogeneous over the entire domain. The background $\mathrm{CCN}$ used in the simulation had a total concentration of $104.4 \mathrm{~cm}^{-3}$, which was similar to the concentrations measured by the Passive Cavity Aerosol Spectrometer Probe (PCASP) during the RICO flights RF11 and RF12 on 7 and 11 January 2005 (J. Hudson 2010, personal communication). However, in order to evaluate the effect of large and giant aerosols, the last five bins in the benchmark STD simulation were set to zero. The last nonzero bin has a dry aerosol radius of $0.129 \mu \mathrm{m}$, corresponding to a wet radius of $0.77 \mu \mathrm{m}$. 

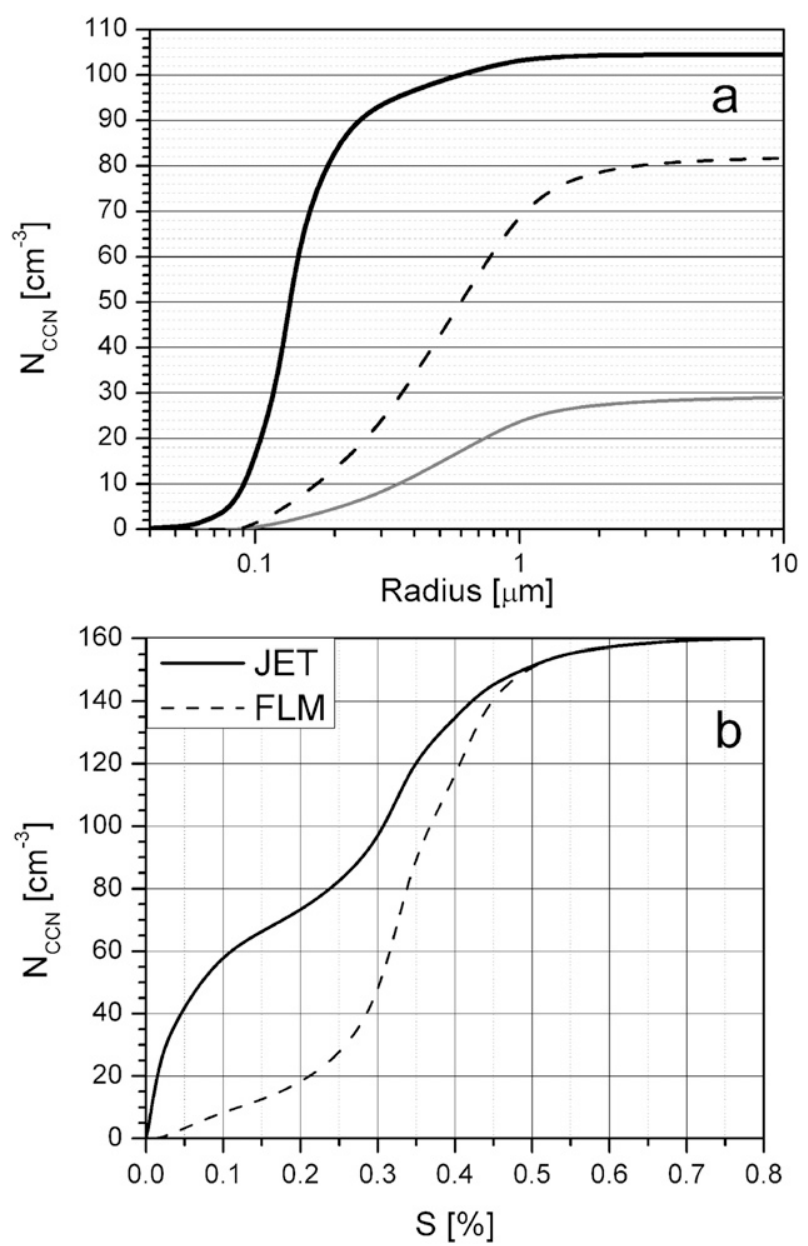

FIG. 2. CCN cumulative spectra for the simulations. (a) The thick black line indicates the spectrum for the STD simulation. The gray and dashed lines represent cumulative distributions of sea-salt nuclei corresponding to surface winds of 12 and $17 \mathrm{~m} \mathrm{~s}^{-1}$ that are added to the STD spectrum in order to construct the TOT and TOT17 spectra, respectively. The radius values under the $x$ axis refer to the "wet" radius, which is the aerosol radius the moment they are activated in the cloud (see Kogan 1991). (b) Cumulative size distributions for the JET and FLM simulations. The total aerosol concentration is the same for both spectra, but the mean radius differs.

The CCN cumulative spectrum as a function of the aerosol wet radius is shown by the thick black line in Fig. 2a.

To test the sensitivity of the precipitation process to the influx of wind-produced sea-salt aerosol from the ocean surface, we performed two additional simulations labeled TOT and TOT17, in which the aerosol distribution of the STD case was supplemented by sea-salt aerosols. The cumulative spectra corresponding to the additional aerosol are indicated by the gray (TOT) and dashed (TOT17) lines in Fig. 2a and correspond to additional sea-salt aerosols with total concentrations of 29.27 and $82.1 \mathrm{~cm}^{-3}$. The TOT spectrum was formulated by employing the exponential relations for "film" and "jet" aerosol modes given by O'Dowd et al. (1997), corresponding to a surface wind speed of $12 \mathrm{~m} \mathrm{~s}^{-1}$, a value consistent with the observed near-surface wind in RICO over that period (Colón-Robles et al. 2006). The TOT17 spectrum represents a limiting case that assumes film and jet aerosol concentrations corresponding to a surface wind speed of $17 \mathrm{~m} \mathrm{~s}^{-1}$. Our imposed sea-salt concentrations differ slightly from those calculated using the O'Dowd et al. (1997) formulas, partly because of an artifact of the spectral discretization but more generally because we employ the O'Dowd et al. relations as a general constraint on the values of sea-salt aerosol concentrations in the film and jet modes. According to Lewis and Schwartz (2004, see their Fig. 22), these concentrations vary in a range spanning about an order of magnitude, depending on environmental conditions.

To mimic the surface flux of sea-salt aerosol in the TOT simulation, the additional aerosols were added only at the lowest two model levels by imposing constant aerosol concentrations in each bin (essentially a specified boundary condition). The aerosols were subsequently transported vertically in the subcloud layer by subgridscale fluxes and turbulent boundary layer eddies resolved by the LES.

In addition to the STD and TOT simulations, two more idealized experiments (FLM and JET) were performed in order to study the sensitivity of the precipitation process to sea-salt aerosols of different sizes. During RICO, the observed low-level wind speeds were at times in the range of $15-17 \mathrm{~m} \mathrm{~s}^{-1}$ [see Fig. 3 of Rauber et al. (2007)]. We therefore assumed a surface-level wind speed of $17 \mathrm{~m} \mathrm{~s}^{-1}$ as a reasonable upper limit of RICO wind speeds and used it to specify jet and film mode aerosol concentrations in these two additional sensitivity experiments. According to O'Dowd et al. (1997), who analyzed data from a large number of observations, sea-salt concentrations for winds speeds of $10-17 \mathrm{~m} \mathrm{~s}^{-1}$ span the $50-100 \mathrm{~cm}^{-3}$ range. We specified a sea-salt concentration of $56.5 \mathrm{~cm}^{-3}$, a value within bounds of measured wind speeds reported in RICO observations. This additional aerosol concentration was imposed at the surface, in addition to the background aerosol from the STD simulation. Because the effect of aerosol on precipitation strongly depends on the average size of the activated CCN, these two experiments distributed this identical concentration of additional $\mathrm{CCN}$ in the range of either predominantly accumulation mode nuclei $(0.02-0.13-\mu \mathrm{m}$ dry radius range; simulation labeled FLM) or in the range of predominantly large and giant nuclei $(0.06-5.5-\mu \mathrm{m}$ dry radius range; simulation labeled JET). The total additional concentrations were identical in the FLM and JET simulations, but the mean radius was changed. The fact that 


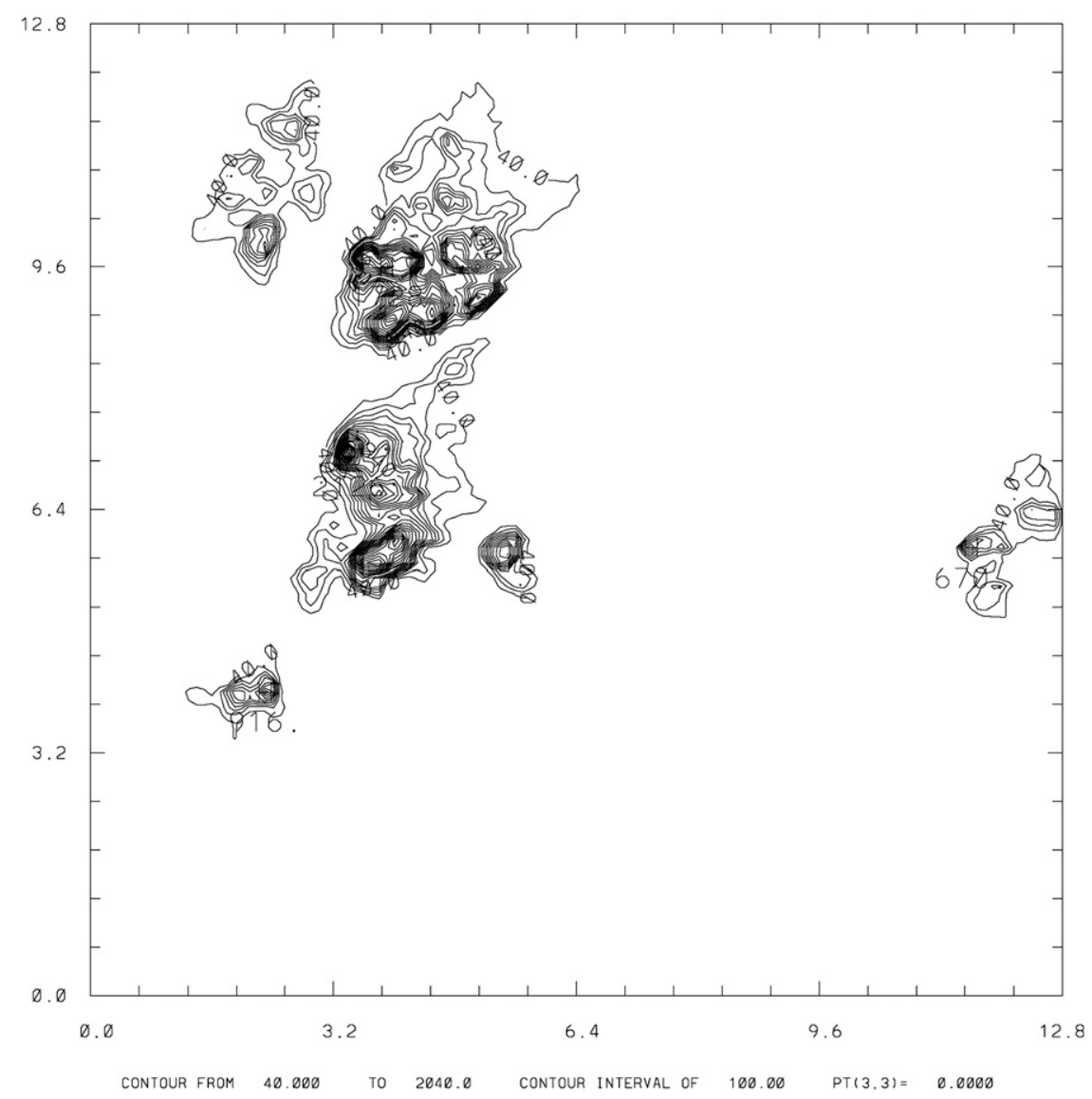

FIG. 3. Snapshot of the liquid water path field at $t=18 \mathrm{~h}$ into simulation. Contour interval is $100 \mathrm{~g} \mathrm{~m}^{-2}$.

the additional aerosol in the FLM and JET simulations were of different sizes is reflected in the activation spectrum (Fig. 2b). The cumulative distributions employed in the FLM and JET simulations are shown in Table 2 and are consistent with the summary of sea-salt aerosol measurements in Lewis and Schwartz (2004).

\section{Simulation results}

\section{a. Behavior of cloud properties}

Our simulation analysis is based on the evolution of 369 unique clouds sampled over the 10-24-h period of the simulation. The liquid water path (LWP) field snapshot at $18 \mathrm{~h}$ (Fig. 3) represents a typical cloud scene in the simulation. Any particular cloud scene may contain a combination of cloud cells at various stages of development. We conditionally sampled the model domain for clouds and then assessed their physical characteristics. The threshold for cloud selection was LWP $>40 \mathrm{~g} \mathrm{~m}^{-2}$. Figure 4 summarizes in cumulative distributions the geometric and primary microphysical characteristics of the 369 clouds sampled over the course of the simulation.
Mean cloud depth $\left(z_{\mathrm{ct}}-z_{\mathrm{cb}}\right)$ is $1.65 \mathrm{~km}$ with a standard deviation of $0.34 \mathrm{~km}$. However, approximately $12 \%$ of cloud cells are deeper than $2 \mathrm{~km}$ (Fig. 4a). Mean cloud volume is $2.26 \mathrm{~km}^{3}$ with a standard deviation of $4.42 \mathrm{~km}^{3}$, which together with Fig. 4a indicates a highly skewed distribution, with roughly $81 \%$ of the clouds having smaller volume than the mean. Thus, the mean cloud volume is dominated by very large clouds that are relatively few in number. The mean cloud cross-sectional area, taken as the average of the LWP areas circumscribed by the $40 \mathrm{~g} \mathrm{~m}^{-2}$ threshold, is $2.01 \mathrm{~km}^{2}$. Generally, the deeper clouds are wider (Zhao and Di Girolamo 2007), a result consistent with wide updrafts being less susceptible to having their buoyancy reduced by entrainment.

Cumulative distributions of liquid water and droplet concentration are both rather symmetric, with the distribution means lying near 50\% cumulative frequency (Fig. 4b). Mean drop concentration, conditionally sampled over cloudy regions, is $36.6 \mathrm{~cm}^{-3}$ with standard deviation of $16.8 \mathrm{~cm}^{-3}$, and the mean cloud liquid water content is $0.32 \mathrm{~g} \mathrm{~m}^{-3}$ with standard deviation of $0.11 \mathrm{~g} \mathrm{~m}^{-3}$. As would be expected, both liquid water content $Q_{l}$ and 


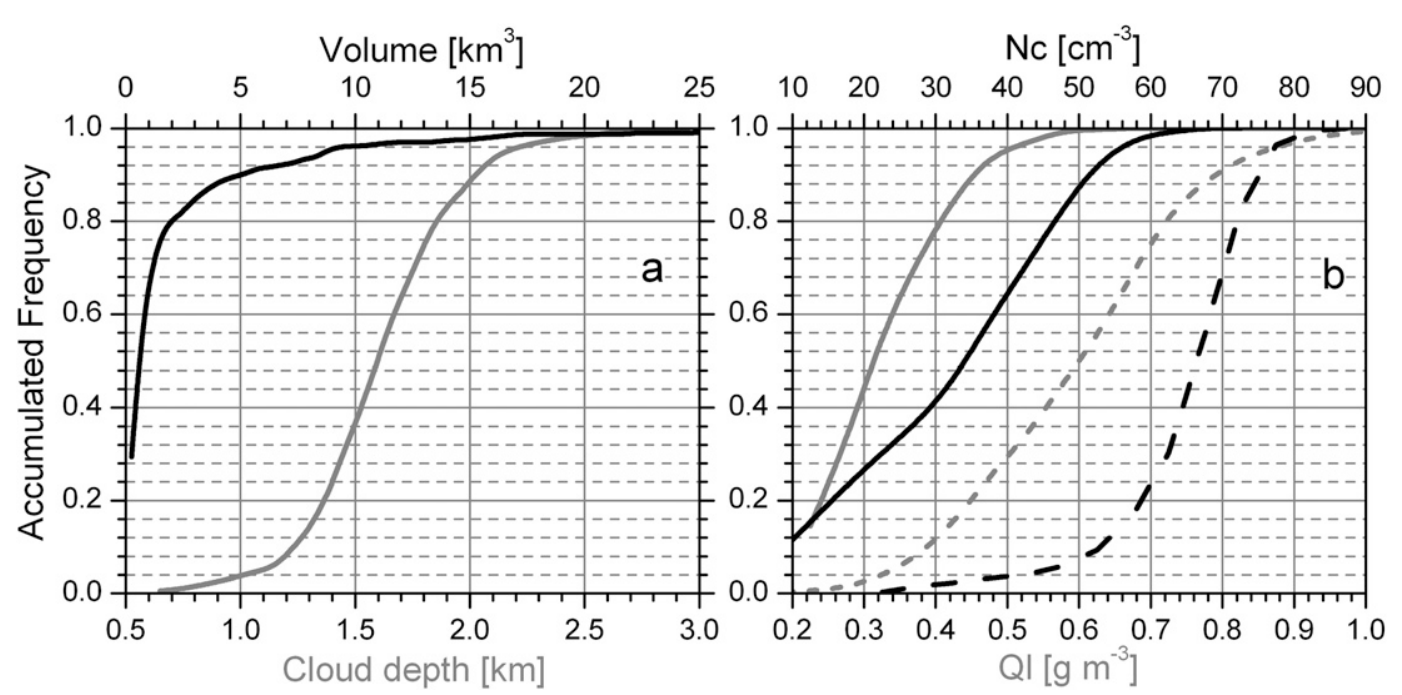

FIG. 4. Cumulative distributions of cloud geometrical and microphysical parameters. (a) Cloud depth (gray) and cloud volume (black). (b) Cloud liquid water (gray) and drop concentration (black). Solid lines correspond to distributions sampled over the entire cloud, whereas dashed lines represent the distributions sampled in regions of positive supersaturation.

droplet concentration $N_{c}$ are drastically greater when conditionally sampled over supersaturated regions (each double that compared to the same quantities over the entire cloud), as these are areas of strong condensational growth and copious droplet nucleation. The cloud cells also merge with time, forming larger multicell clusters, which produce precipitation-induced cold outflows that in turn promote more cloud formation. This effect reflects the feedback between cloud and precipitation noted by Stevens and Feingold (2009).

Statistical characteristics from subjectively chosen examples of two different stages of the cloud life cycle are shown in Fig. 5. Small young cells are predominantly dominated by updrafts (Fig. 5b) ranging over a layer several hundred meters deep from cloud base upward. At a level of $1.45 \mathrm{~km}$, updrafts and downdrafts are equally likely, with the distribution skewed toward a greater probability of stronger updrafts. Above $1.5 \mathrm{~km}$, the cloud is slightly downdraft-dominant, which is consistent with the development of precipitation beginning in the mid and upper levels of the cloud. In the mature stage (Fig. 5a), downdrafts are present throughout the depth of the cloud. The distribution indicates that at this stage vertical moisture flux is provided by strong updrafts that are relatively few in number, which would be expected to weaken as the clouds transition to their decaying stage.

\section{b. Effects of sea-salt aerosols on cloud-base parameters}

We focus on how sea-salt aerosols influence the microphysical properties of the layer at and just above cloud base, defined in this study as the 160-m layer from 600 to $760 \mathrm{~m}$. We further subdivided the cloud into three additional layers: lower middle (800-1000 m), upper middle (1000-1800 m), and cloud top (1800 m to cloud top). Figure 6 shows the dependence of cloud supersaturation and cloud drop concentration at cloud base on vertical velocity for the benchmark STD experiment. Drop concentration was conditionally sampled over regions of positive supersaturation $(S>0)$, which corresponded predominantly to regions of positive vertical velocity. Clouds characterized by stronger cloud-base updrafts are associated with larger supersaturation $S$, leading to a greater number of activated cloud droplets (larger $N_{c}$ ). Both supersaturation and cloud drop concentration are well correlated with vertical velocity (correlation coefficient $R \approx 0.8$ ). It is worth noting that because of the nonlinear relation between supersaturation and activated drop concentration, using a mean cloud supersaturation in a typical nucleation parameterization (e.g., $N_{c}=C s^{k}$ ) will underestimate the activated drop concentration. For example, a mean supersaturation of $0.2 \%-0.3 \%$ applied to the FLM activation spectrum in Fig. 3 would activate only $20-40 \mathrm{~cm}^{-3}$, whereas the actual cloud base concentration in the FLM case varies between 60 and $120 \mathrm{~cm}^{-3}$ (see Fig. 8 b below). This nonlinearity suggests that nucleation should be integrated over the probability distribution function of $S$ or $W$ in order to obtain an unbiased estimate of the nucleated droplet concentration. Similar relationships (not shown) exist for all four cloud layers in areas of positive supersaturation. This robust dependence on vertical velocity is the basis for a number of parameterizations of cloud-base droplet 

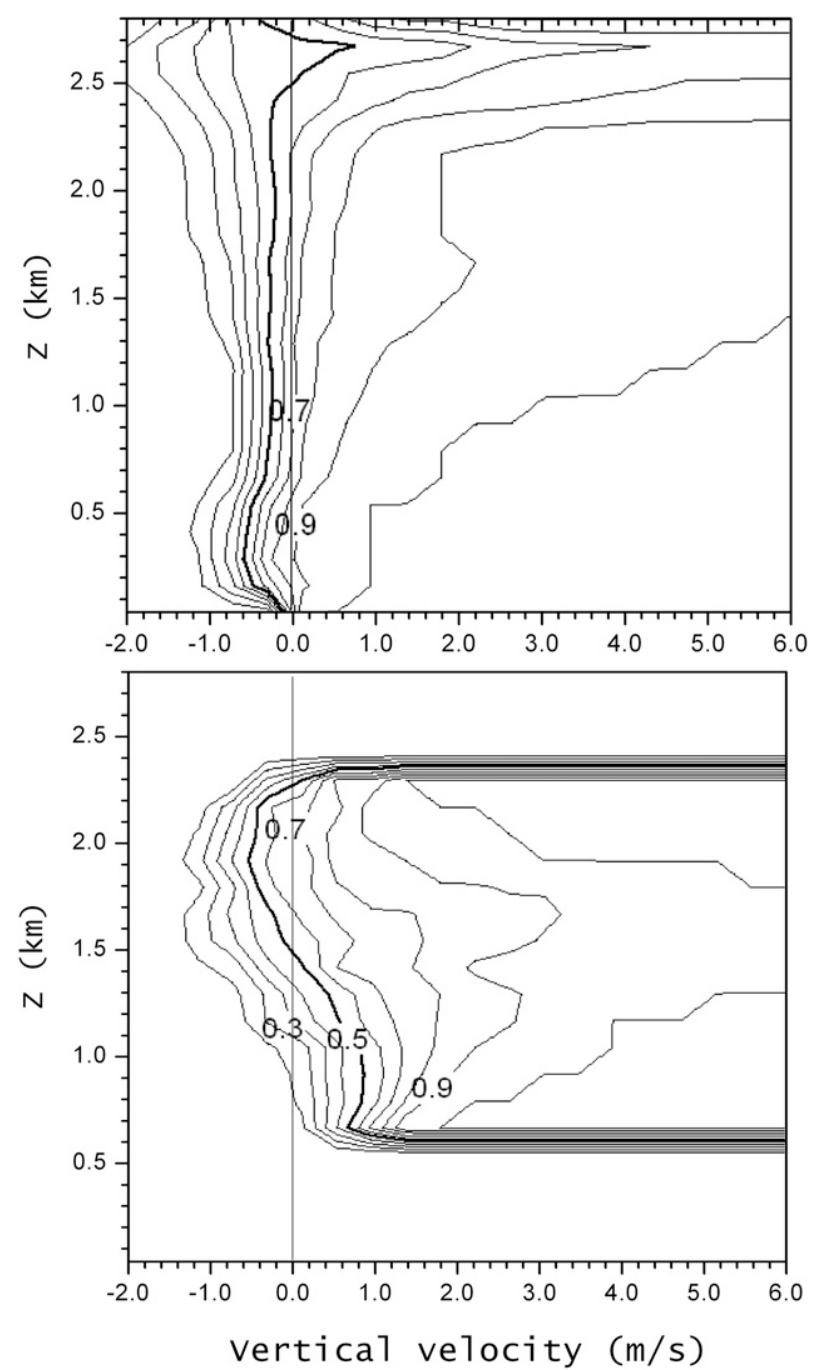

FIG. 5. Cumulative distribution of vertical velocity stratification in (top) a mature multicell and (bottom) a growing single-cell cloud.

nucleation (e.g., Twomey 1959; Abdul-Razzak et al. 1998; Cohard et al. 1998; Snider et al. 2003).

Figure 7 shows the dependence of rain drop concentrations (drop radii greater than $20.2 \mu \mathrm{m}$ ) on vertical velocity in regions of positive supersaturation for all four vertical layers in the STD simulation. The simulation exhibits an inverse relationship between rain drop concentration $N_{r}$ and vertical velocity $W$ at cloud base. These two quantities do not appear to be related over the lowermiddle layer, whereas over the upper-middle and cloudtop layers $N_{r}$ and $W$ are positively correlated. The positive correlation in the upper half of the cloud is consistent with the formation of precipitation embryos via autoconversion in an environment of large liquid water content. The increase in rain drop concentration with height by two orders of magnitude (from 0.2 to $20 \mathrm{~cm}^{-3}$ ) reflects
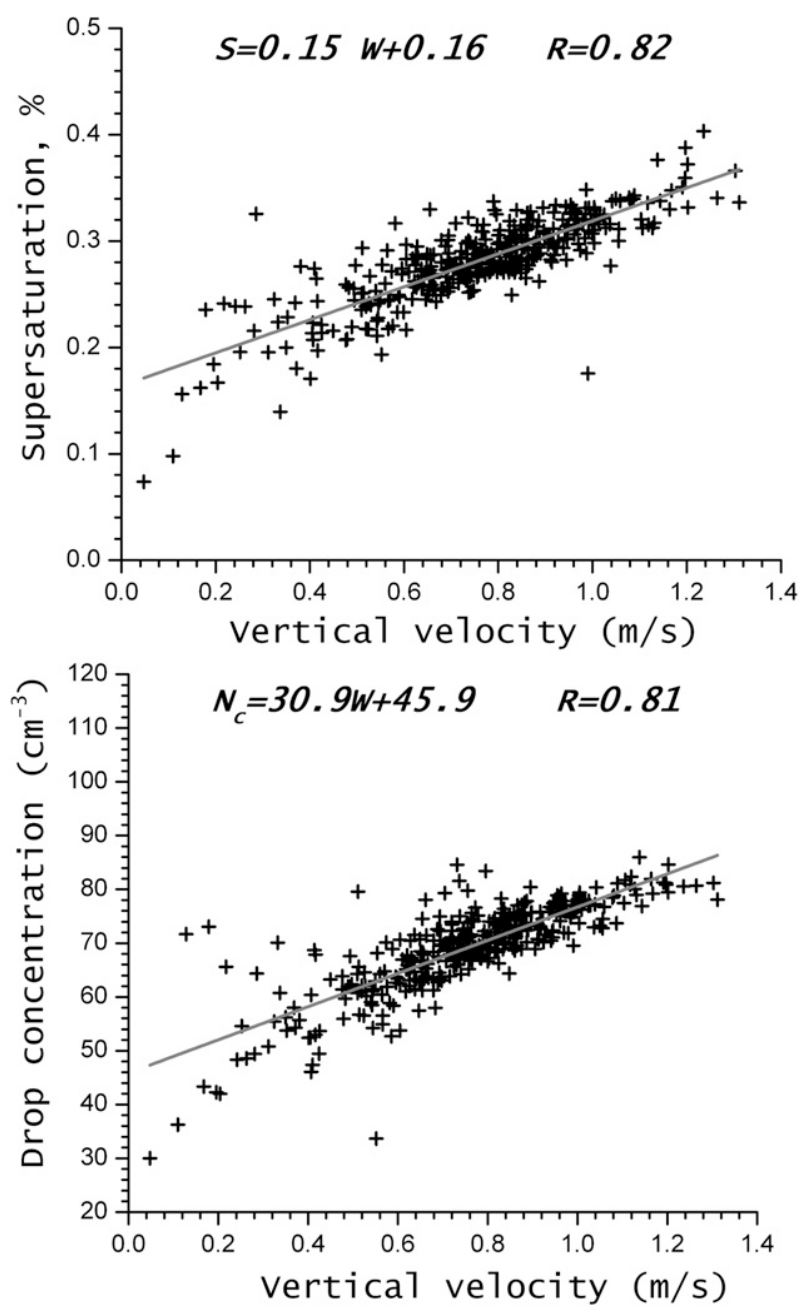

FIG. 6. The scatterplots of (top) average supersaturation and (bottom) cloud drop concentration $N_{c}$ vs average vertical velocity $W$ at cloud base in the STD simulation.

the balance between the increase in concentration attributable to autoconversion and the decrease from self-collection. The correlation between $N_{r}$ and $W$ is poor over all layers in areas of negative supersaturations (not shown); the latter roughly coincide with downdraft regions.

The negative correlation between $N_{r}$ and $W$ at cloud base is consistent with observational results from RICO (Colón-Robles et al. 2006), in which stronger updrafts were associated with smaller mean droplet size (and, by implication, fewer precipitation embryos; see Fig. 1). At first glance, the inverse relation between strength of the updraft and production of rain drops seems counterintuitive, as more vigorous clouds generally produce more rain. Larger rain rates indeed accompany stronger updrafts, but as the results of section $4 \mathrm{c}$ below demonstrate the majority of precipitation falls through regions of downdraft. The inverse $N_{r}-W$ relationship, on the other 

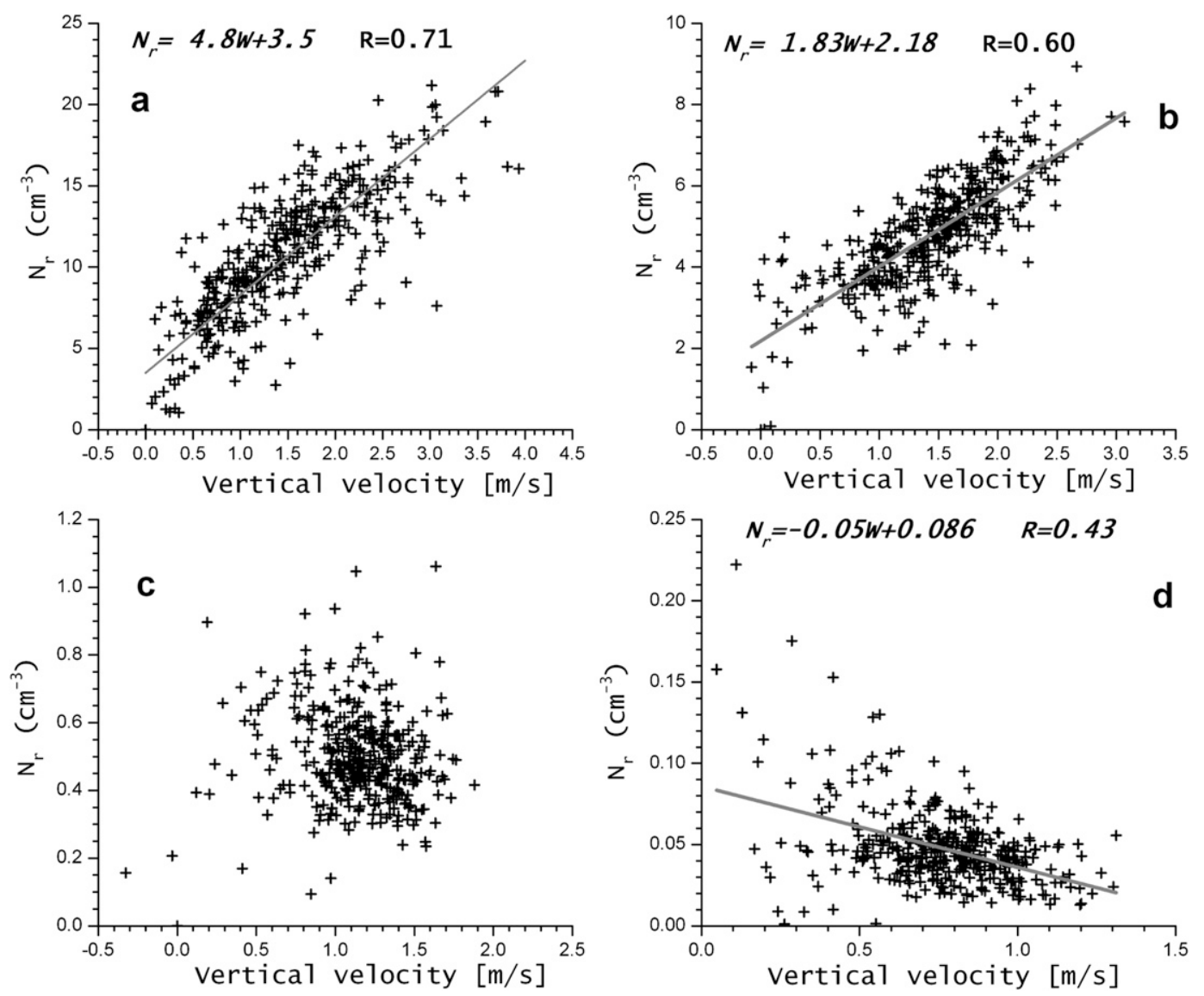

FIG. 7. Scatterplots of $N_{r}$ vs $W$ for four vertical layers: (a) cloud top (1800 m-top), (b) upper middle (1000-1800 m), (c) lower middle (800-1000 m), and (d) cloud base (600-760 m). The clouds are conditionally sampled over regions of positive supersaturation, which correspond predominantly to updraft areas in the cloud.

hand, applies only to cloud-base updrafts. These cloudbase updrafts are zones not only of cloud-drop nucleation, but also of precipitation embryo formation. For this reason, the behavior of $N_{r}$ at cloud base directly assesses the primary impact on precipitation of aerosol in general, and GCCN in particular.

In the absence of the GCCN effects, the negative $N_{r}-W$ correlation is consistent with traditional Köhler theory whereby activation of smaller nuclei accompanies stronger updrafts, which then compete for moisture to the detriment of embryonic rain drop formation. Thus, the observed $N_{r}-W$ behavior in RICO and simulated here suggests that GCCN play only a minimal role in the precipitation process for this specific case.

We now consider the two additional simulations (JET and FLM) described in section 3b. In the cloud-base layer, the FLM simulation exhibits larger average supersaturations $S$ (Fig. 8a) and correspondingly larger total drop concentrations $N_{t}$ (Fig. 8b). As expected, the rainwater fraction (relative to the total liquid water content) in FLM is smaller (Fig. 8c), a result consistent with the much smaller size of the additional aerosol added in the FLM simulation. However, the cloud liquid water content $Q_{l}$ (Fig. 8d) is smaller as well, which is somewhat unexpected.

The difference in cloud-base rainwater fraction and $Q_{l}$ is explained from a more detailed analysis of the cloudbase activation process and its influence on different drop sizes. For this, we divided the cloud drop range into two categories: one for small cloud droplets (SCD) with radii smaller than $10.1 \mu \mathrm{m}$ and another for large cloud droplets (LCD) with radii in the range from 10.1 to $20.2 \mu \mathrm{m}$. As before, the rain drop (RD) category contains drops with radii larger than $20.2 \mu \mathrm{m}$. To aid in the analysis, we also show in Fig. 9 the linear fits for $S$ and $N_{t}$ as a function of $W$, along with the corresponding values of the correlation coefficients.

The large and giant cloud condensation nuclei present in the JET simulation are easily activated in sufficiently large numbers even at small supersaturations. As a result, at smaller values of updraft $\left(W<0.45 \mathrm{~m} \mathrm{~s}^{-1}\right), N_{t}$ in the JET simulation is larger (Fig. 9a), in accordance 

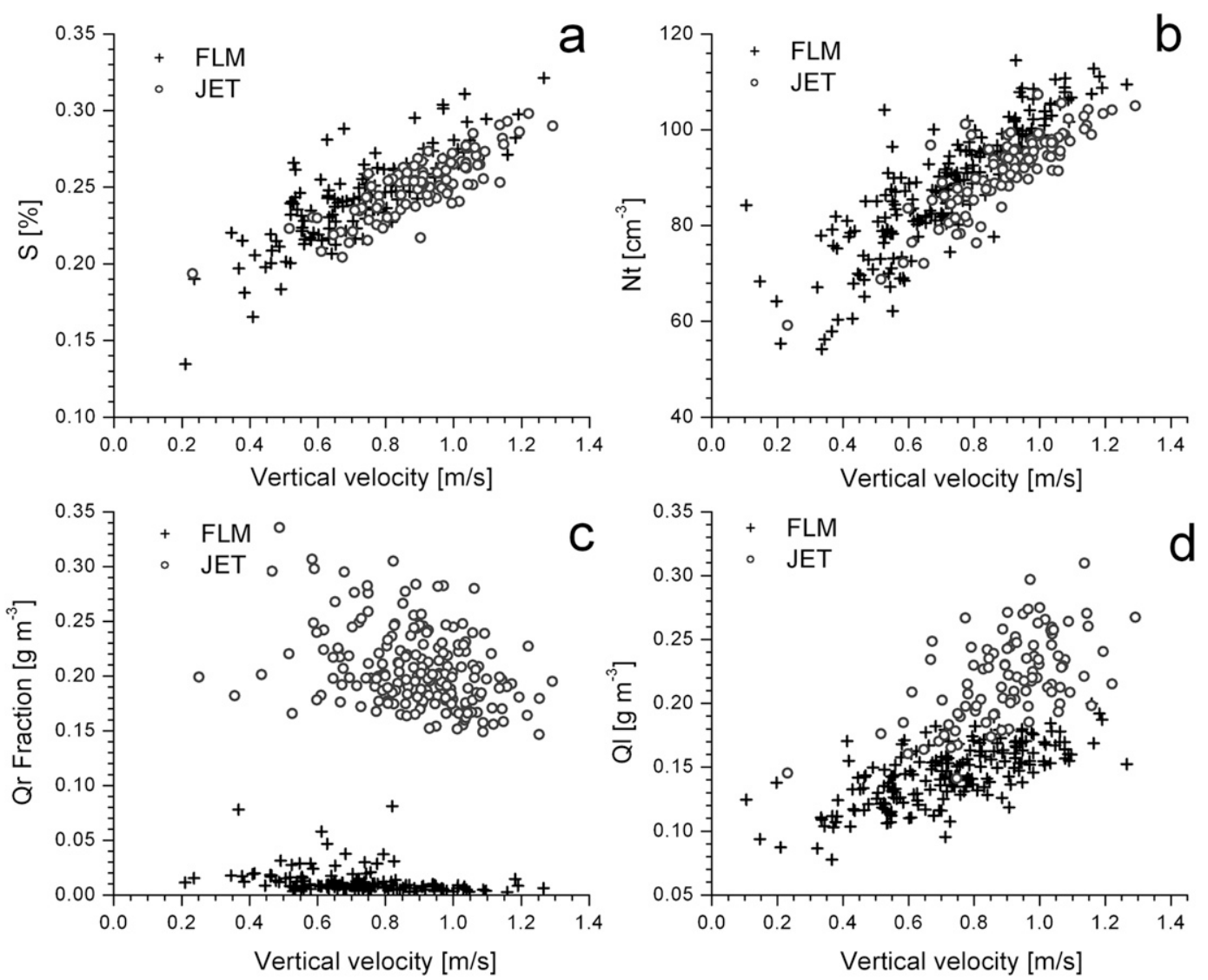

FIG. 8. Scatterplots of cloud-base mean microphysical quantities as a function of vertical velocity $W$ for the JET and FLM simulations. Each point represents cloud-base mean quantities, and values in the $N_{t}, Q_{l}$, and $Q_{r}$ fraction panels are conditionally sampled over regions of positive supersaturation. (a) Supersaturation $S$; (b) total drop concentration $N_{i}$; (c) $Q_{r}$ (rainwater) fraction; (d) liquid water content $Q_{l}$.

with the CCN spectrum shown in Fig. 2. The condensation in the LCD and RD categories damps the further growth of supersaturation, which remains smaller for all updrafts, relative to the FLM case (Fig. 9b). Supersaturation excess (above the Köhler equilibrium value), therefore, is somewhat self-limiting in the JET simulation.

For the FLM simulation, the lack of large and giant $\mathrm{CCN}$ that would otherwise compete for water vapor and reduce supersaturation instead allows supersaturation $S$ to grow to larger values (Fig. 9b). The larger supersaturations lead to more activation and increase the total drop concentration (Fig. 9a), which at updrafts larger than $0.45 \mathrm{~m} \mathrm{~s}^{-1}$ exceeds that of the JET case. However, these larger values are mostly due to the increase of small-sized drops (indicated by crosses in Fig. 10a). The small cloud droplets, however, have a limited capacity to remove water vapor excess, as the rate of condensation is roughly proportional to the integral mean drop radius (the integral of the drop radius over the corresponding drop size range). The mean drop radius is indeed smaller in the FLM simulation than in the JET case. So, despite a larger drop concentration in the FLM case, the amount of condensation and the resulting liquid water $Q_{l}$ are both smaller than for the JET case (Fig. 10d). On the other hand, the larger integral mean drop radius in the JET simulation results in more rapid growth of large cloud drops and rain drops. These two categories contribute most to the larger $Q_{l}$ values in the JET simulation (Figs. 8d and 10d).

The other effect essential for the explanation of the $N_{r}-W$ relation in the FLM case is the smaller coalescence efficiency associated with smaller drops, which suppresses the production of rain drops. The latter is the prime reason for the inverse relation between $N_{r}$ and $W$.

Figure 11 summarizes the $N_{r}-W$ relationship at cloud base for the four simulations. The parameters for the four linear regression lines are given in Table 3:

$$
N_{r_{i}}=a_{i}+b_{i} \times W
$$




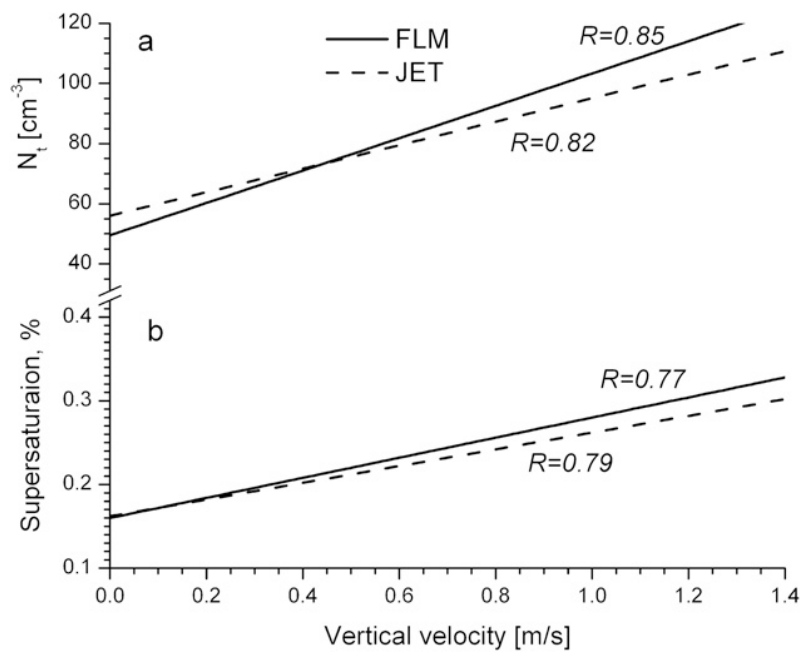

FIG. 9. Linear fits of cloud-base supersaturation and total drop concentration $N_{t}$ vs $W$ for the JET and FLM simulations. The corresponding correlation coefficient $R$ is shown for each line.

The slope of the linear best-fit line $b_{i}$ is negative in cases where large sea-salt aerosols are absent, and the slope is positive for an environment containing an abundance of large sea-salt aerosols. These results suggest that the slope of the $N_{r}-W$ relationship at cloud base may serve as an indicator of the role of sea-salt aerosols produced by surface winds. For this specific case of RICO trade cumulus, the simulation suite is consistent with the observational findings of Colón-Robles et al. (2006), Hudson and Mishra (2007), Knight et al. (2008), Hudson et al. (2009), Nuijens et al. (2009), and Reiche and LasherTrapp (2010), which indicate that GCCN in the form of large sea-salt aerosol played only a minor role in the precipitation process in the RICO campaign. Our simulation results of the role of GCCN, however, should not be generalized for conditions other than those observed during RICO simulations.

\section{c. Effects of sea salt on precipitation}

For the analysis of precipitation formation in the vertical, we consider, in addition to the $160-\mathrm{m}$ cloud base layer, the three additional cloud layers defined in section $4 \mathrm{~b}$ and Fig. 7: the lower-middle 200-m-thick layer from 800 to $1000 \mathrm{~m}$, the upper-middle 800 -m-thick layer from 1000 to $1800 \mathrm{~m}$, and a top layer of variable thickness located from $1800 \mathrm{~m}$ up to the top of each individual cloud.

Figure 12 shows precipitation rates for the benchmark simulation (STD), averaged over the corresponding cloud layer and stratified by positive and negative supersaturation. Predominantly these areas are associated with updrafts and downdrafts, respectively. However, a number of points with negative supersaturations are located in weak updrafts and vice versa, as evident from
TABLE 3. Parameters of the linear fit (1): $a_{i}$ and $b_{i}$ are the offset and slope of the linear fit, and $R$ is the correlation coefficient.

\begin{tabular}{ccccc}
\hline \hline Index $i$ & Label & \multicolumn{1}{c}{$a_{i}$} & \multicolumn{1}{c}{$b_{i}$} & $R$ \\
\hline 1 & FLM & 0.056 & -0.033 & 0.39 \\
2 & STD & 0.0858 & -0.05 & 0.43 \\
3 & TOT & 0.141 & 0.07 & 0.48 \\
4 & JET & 0.34 & 0.20 & 0.58 \\
\hline
\end{tabular}

overlapping color symbols in the left-column panels of Fig. 12. As expected, precipitation in updrafts increases with height, while the opposite is true in downdrafts where precipitation at lower cloud levels significantly exceeds updraft precipitation. Updraft core fraction (Fig. 12, right panels) shows the fraction of cloudy core (defined as $S>0$ ) and is stratified by cloud thickness. The core fraction for small clouds (less than $1.8 \mathrm{~km}$ deep and less than $3 \mathrm{~km}^{3}$ in volume) at most layers is less than $25 \%-30 \%$; for more mature clouds of medium and large size (deeper than $1.8 \mathrm{~km}$ and larger than $3 \mathrm{~km}^{3}$ in volume) the core is less than $10 \%$ of the volume, an indication that downdrafts dominate the structure of these clouds.

The effect of different surface sea-salt aerosols is demonstrated in Fig. 13, which shows accumulated surface precipitation and vertical profiles of cloud cover. The two experiments with high concentrations of jet and film aerosols (JET and FLM, respectively) produce the largest $(0.47 \mathrm{~mm})$ and the smallest $(0.05 \mathrm{~mm})$ precipitation magnitudes (Fig. 13a). The background experiment with no additional sea salt (STD) led to an intermediate amount of precipitation $(\sim 0.22 \mathrm{~mm})$. The TOT simulation, in which both film and jet sea-salt aerosols were present in more realistic concentrations corresponding to surface winds of $12 \mathrm{~m} \mathrm{~s}^{-1}$, produces an accumulated precipitation of $\sim 0.34 \mathrm{~mm}$. The additional film-size aerosol particles act to increase the total concentration of cloud drops, which suppresses precipitation formation. The relatively small concentration of large jet aerosol $\left(1.9 \mathrm{~cm}^{-3}\right)$, on the other hand, provides sufficient number of drizzle embryos which seems to overcome the damping effect of the film aerosol. The effect of the jet mode dominates, resulting in approximately $30 \%$ increase in accumulated precipitation. Thus, knowledge of total aerosol concentration alone is not sufficient to describe or predict trade cumulus precipitation. The relative composition of small and large sea-salt aerosols reaching the cloud layer is crucial in understanding the shallow cumulus precipitation process.

According to the parameterization suggested by O'Dowd et al. (1997), this relative composition of film and jet sea-salt aerosol depends exponentially on wind speed. Because of this exponential dependence, increasing the 

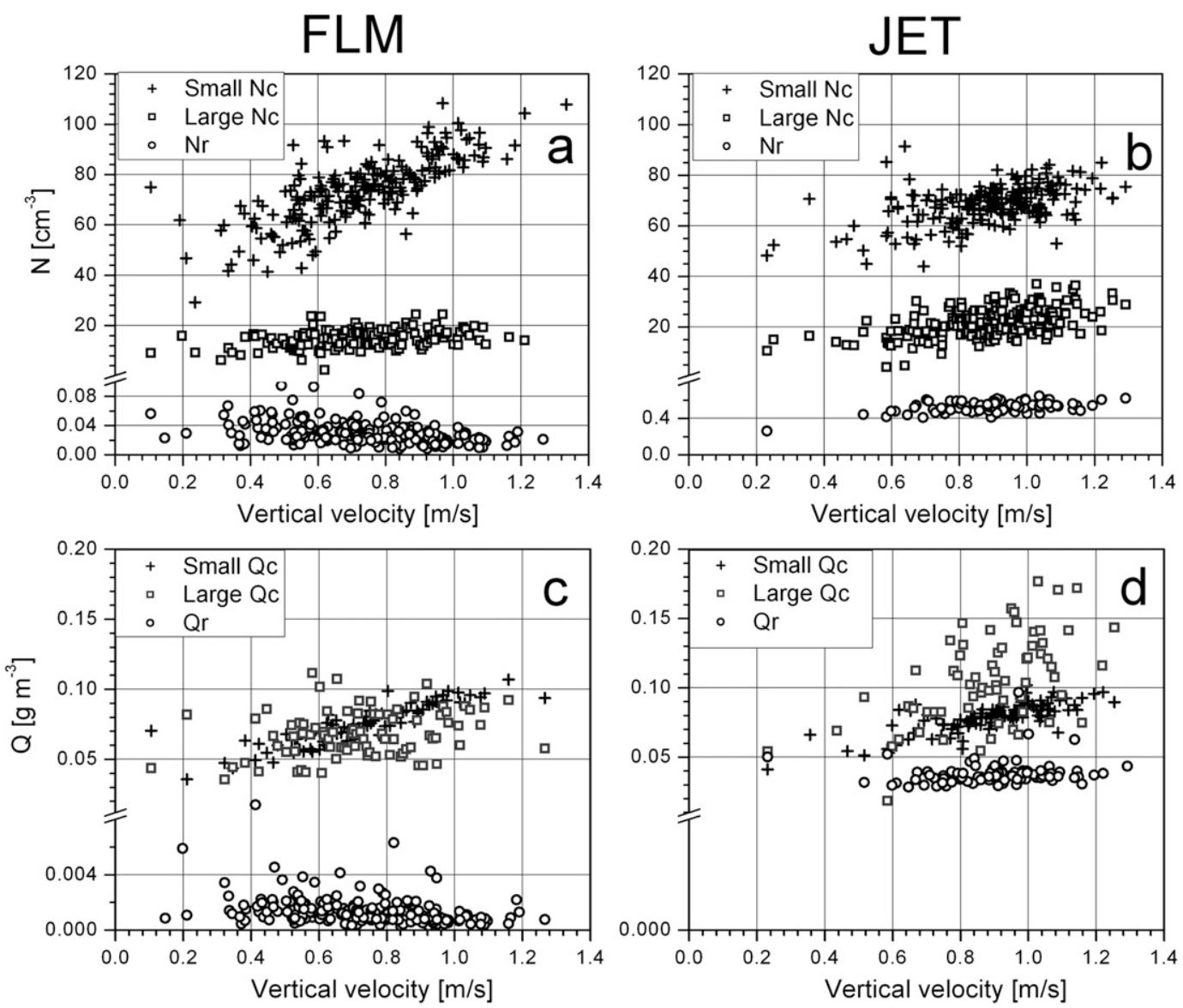

FIG. 10. (top) Cloud-base drop concentration $N_{c}$ and (bottom) cloud liquid water content $Q_{l}$ at vs $W$ for (left) FLM and (right) JET simulations in categories of small cloud drop, large cloud drop, and rain drop.

wind speed from 12 to $17 \mathrm{~m} \mathrm{~s}^{-1}$ results in nearly a tripling of film aerosol (from 27 to $79 \mathrm{~cm}^{-3}$ ) but only a $40 \%$ increase in jet aerosol (from 1.9 to $2.7 \mathrm{~cm}^{-3}$ ). To explore the effect on precipitation of this variation in relative composition, we performed an additional simulation (TOT17) that specified a surface source of film and jet modes corresponding to a wind speed of $17 \mathrm{~m} \mathrm{~s}^{-1}$. We compared this TOT17 simulation with the TOT results, which assumed a wind speed of $12 \mathrm{~m} \mathrm{~s}^{-1}$.

Results of the TOT and TOT17 simulations (Fig. 13a) indicate that increasing wind speed is accompanied by an increase in precipitation. In the specified background $\mathrm{CCN}$ environment, drizzle embryos associated with the jet aerosol play a more pronounced role than the increase in total CCN concentration from the film aerosol. This is a remarkable result and points to the effectiveness of large sea-salt nuclei, particularly given that the large number of added film nuclei contribute both to lower coalescence efficiencies and, because of their large total surface area, increasingly compete for available water vapor and reduce the supersaturation field.
Characteristics of the background $\mathrm{CCN}$ spectrum are also important. The same TOT and TOT17 simulations, but in an environment with a higher background aerosol load (hiTOT and hiTOT17, which assumed a larger background aerosol concentration of $154 \mathrm{~cm}^{-3}$, consistent with the RICO RF14 case) demonstrate a sensitivity opposite to that of TOT and TOT17. As Fig. 13b shows, the increase in wind speed from 12 to $17 \mathrm{~m} \mathrm{~s}^{-1}$ results in a remarkable decrease in accumulated precipitation. Although a comprehensive evaluation of the sensitivity to background $\mathrm{CCN}$ characteristics is beyond the scope of this study, it is worth emphasizing that the precipitation process depends on both the background $\mathrm{CCN}$ characteristics and the surface sea-salt source, a result similar to what previous studies have demonstrated for droplet nucleation in marine stratocumulus (e.g., Ghan et al. 1998).

A decrease in cloud cover generally accompanies larger precipitation rates, although the result is height dependent (Fig. 13c). It is worth noting also that the precipitation rates in different aerosol environments 

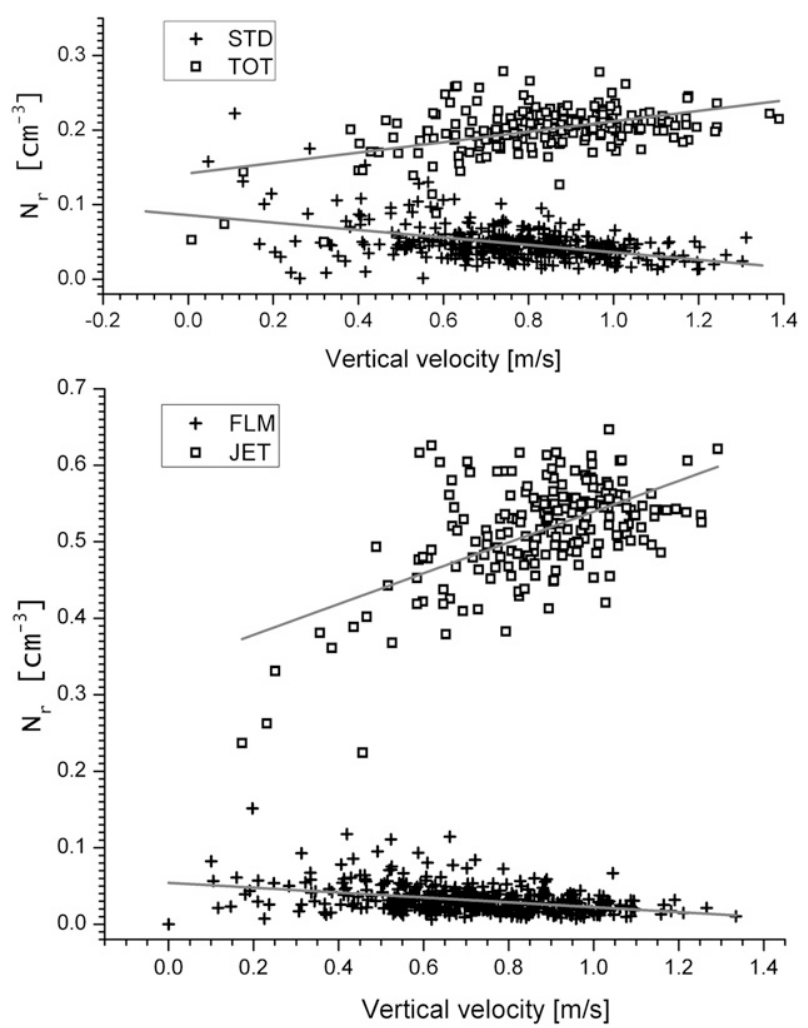

FIG. 11. Scatterplots of $N_{r}$ at cloud base vs $W$ for the four simulations: (top) STD and TOT and (bottom) FLM and JET. Data are sampled over the cloudy regions of positive supersaturation, which largely corresponds to updraft areas.

typically exhibit large fluctuations, even when averaged over periods as long as $4 \mathrm{~h}$. This behavior is a consequence of negative feedbacks or buffering in the cloud system (Stevens and Feingold 2009) and must be kept in mind in analysis of both numerical simulation output and observational data. Over the 4-h averaging interval in this particular suite of experiments, cloud fraction at higher levels (e.g., $z=2 \mathrm{~km}$ ) is largest in the FLM simulation, which is consistent with its smallest drizzle rate. The STD simulation showed a sharp increase in precipitation over the last $2 \mathrm{~h}$, and we would expect that averaged over a longer period the STD cloud fraction would be somewhat less at all heights than cloud fraction in the FLM experiment. In the more strongly precipitating cases (JET, TOT, and TOT17), cloud cover decreases with height, reflecting formation of more vigorous clouds with subsequent depletion of liquid water by precipitation in the middle and upper layers. In cases with less precipitation, the cloud cover increases at upper layers, although the relationship is not uniformly linear with altitude.

Profiles of cloud system thermodynamic variables and turbulent fluxes, averaged over the last four simulation hours, further illustrate the effects of sea salt (Fig. 14). The control simulation is roughly similar to the SAMEX submission in the GCSS RICO intercomparison (van Zanten et al. 2011) and exhibits robust precipitation production. The boundary layer exhibits the nearly wellmixed subcloud layer and stably stratified cloud layer characteristic of the trade cumulus environment. Except for a shallow layer near cloud base and up higher near the trade inversion, buoyancy flux is positive, indicating that cloud updrafts on average contribute to buoyancy production of turbulent kinetic energy over their entire depth.

Smaller cloud water content in the JET and TOT simulations is consistent with the larger precipitation rates in those cases. This close link between precipitation and cloud water suggests that precipitation acts primarily as a sink for liquid water, with precipitationinduced dynamical feedbacks playing a secondary role. The response of rainwater $Q_{r}$ fluctuates greatly with time, and total accumulated rain amounts across the four simulations are not necessarily reflected in the ordering or shape of $Q_{r}$ profiles. The cases producing the greatest amount of precipitation over the course of the simulations (JET and TOT) exhibit the smallest values of vertical velocity variance and buoyancy flux. It is interesting that these two parameters have a nonlinear response to change in accumulated precipitation. For instance, in both STD and FLM the differences in profiles of vertical velocity variance and buoyancy flux are much smaller than the differences in accumulated precipitation; the same is true for simulations JET and TOT (Fig. 13a). The weaker profiles of turbulent intensity and buoyancy production accompanying increased precipitation are associated with smaller entrainment rates. The suppressed entrainment via precipitation is reflected not only in boundary layer depth but also in the potential temperature and water vapor profiles, as the strongly precipitating cases are cooler and moister than the simulations with weaker precipitation rates.

\section{Conclusions}

Despite the well-established effects of giant cloud condensation nuclei (GCCN) on precipitation, their role under specific atmospheric conditions still remains ambiguous and the subject of continuous scientific debate. Theoretical and modeling studies [see, e.g., Cooper et al. (1997) and references therein] suggest that the uncertainty may be due to the competing effects of small versus large cloud drops, and the presence of embryonic rain drops formed on giant $\mathrm{CCN}$. As a result, the overall effect on precipitation in specific conditions depends on the balance between the concentration of small- and 

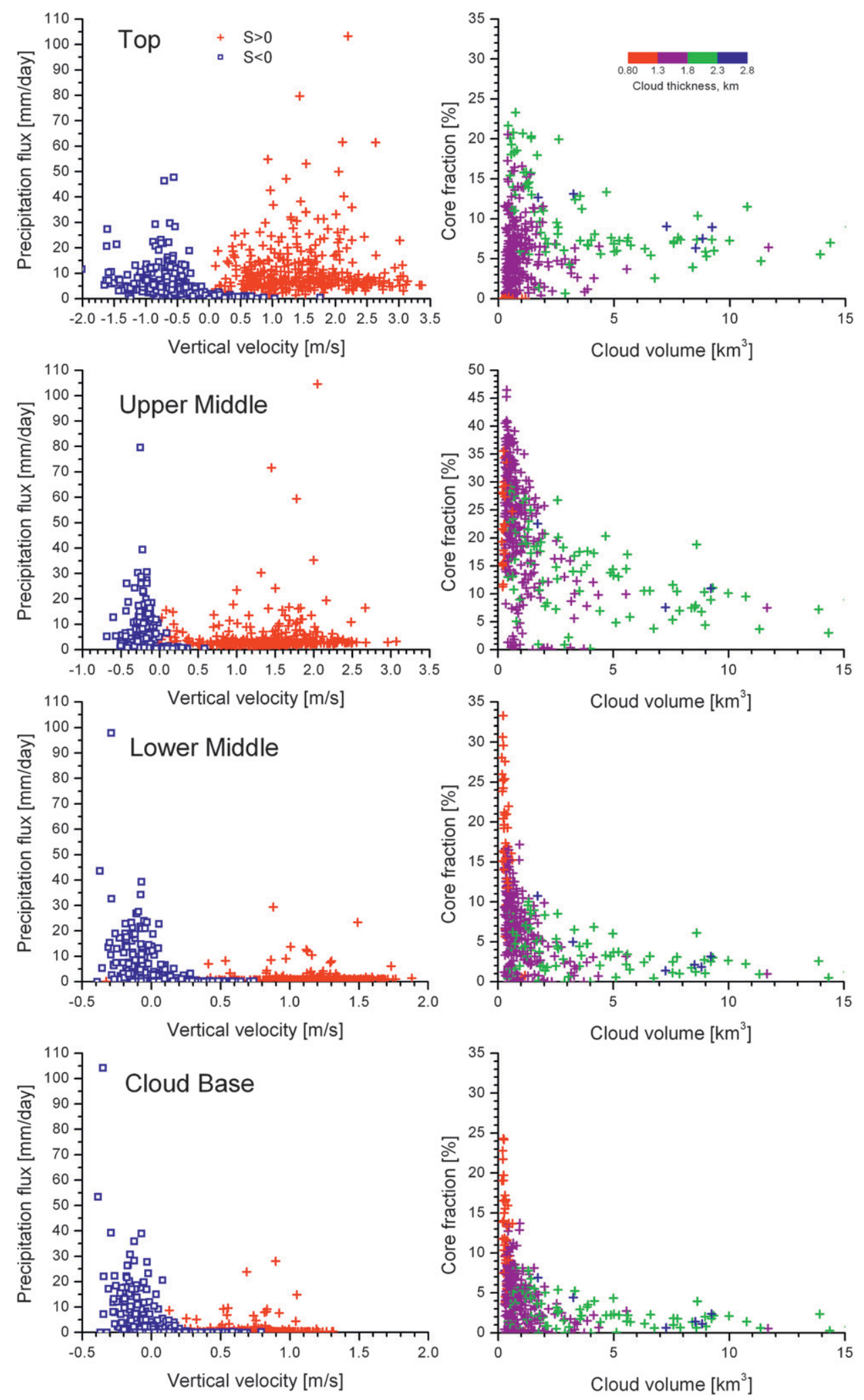

FIG. 12. (left) Scatterplots of precipitation flux vs $W$ for (top to bottom) the four vertical layers from cloud top to cloud base. Red pluses and blue squares correspond to positive and negative supersaturation areas respectively. (right) Scatterplots of the fraction occupied by areas of positive supersaturation stratified by cloud thickness. 

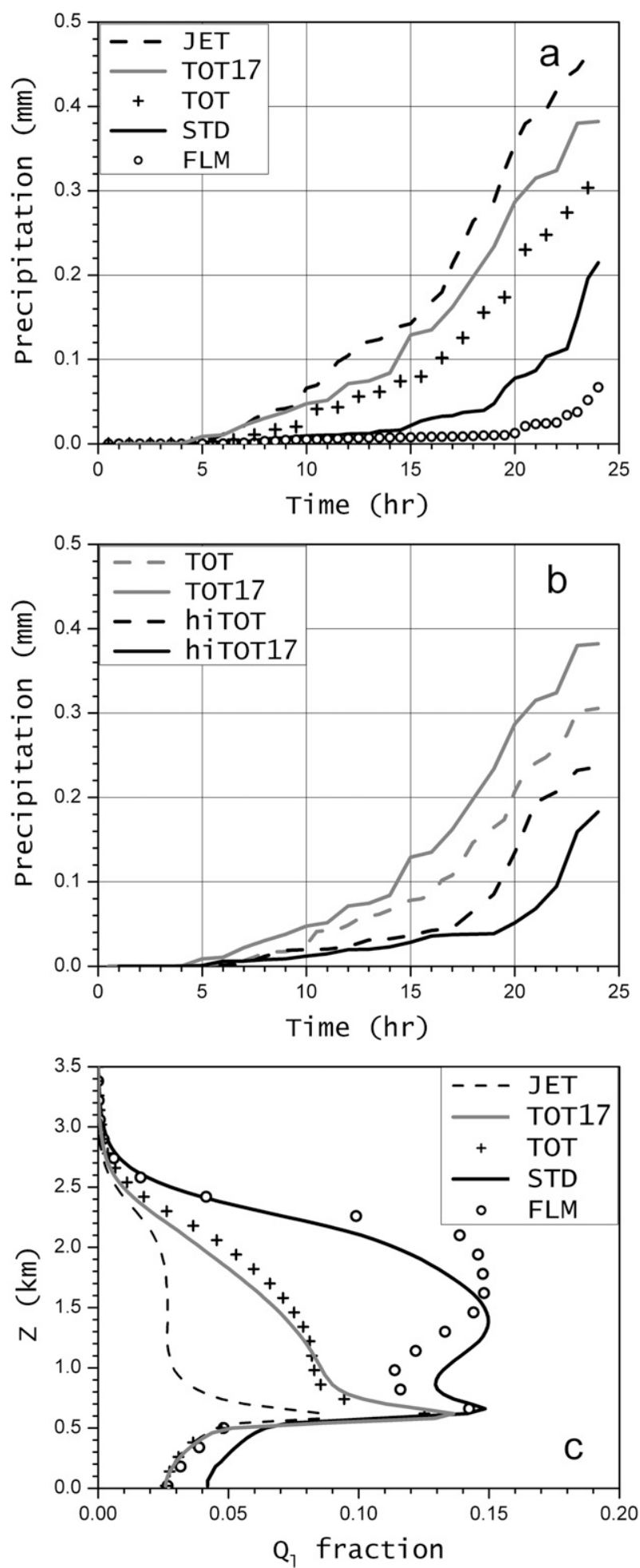

FIG. 13. (a) Evolution of the accumulated surface precipitation for five simulations. (b) Accumulated surface precipitation for the TOT and TOT17 simulations as in (a), together with corresponding hiTOT and hiTOT17 simulations, which employed a larger background $\mathrm{CCN}$ environment. (c) Profiles of liquid water fraction averaged over the last $4 \mathrm{~h}$ of simulation. large-sized drops. The indirect manifestation of this balance was noted in the observational study of ColónRobles et al. (2006). They showed that in RICO, updrafts at cloud base were associated with large droplet concentrations, small droplet mean radius, and a paucity of large droplets just above cloud base. Therefore, at cloud base the concentration of precipitation embryos $N_{r}$ and updraft magnitude $W$ were negatively correlated. This correlation is consistent with the dependence on updraft strength of a typical aerosol distribution composed predominantly of submicron CCN. Hudson and Mishra (2007) also found a negative correlation between background $\mathrm{CCN}$ concentration and the mean cloud drop diameter near the cloud base layer, suggesting that submicron $\mathrm{CCN}$ exerted a greater influence than GCCN in RICO precipitation initiation. The studies of Gerber et al. (2008) and Lowenstein et al. (2010), on the other hand, point to a greater role of GCCN in the precipitation process in RICO.

The purpose of this study was to investigate the combined effects of film and jet sea-salt aerosols under conditions characteristic of shallow trade wind cumulus observed during the RICO project. Following the findings of by Colón-Robles et al. (2006), we also studied the correlation between large drop concentration and vertical velocity at cloud base. Our analysis was based on a suite of large-eddy simulations with size-resolving microphysics; each simulation provided a population of 369 cloud cells over a 14-h period. The baseline simulation included only the background CCN spectrum (STD), which was contrasted against a simulation that added sea salt at the surface corresponding to observational wind magnitudes of 12 (TOT) and $17 \mathrm{~m} \mathrm{~s}^{-1}$ (TOT17). Two additional idealized simulations (JET and FLM) tested the effect of adding a large concentration of sea-salt aerosol in two different size ranges. Because of the large concentrations of additional sea salt, the JET and FLM simulations should be viewed as limiting, rather than observationally justified, cases.

The analysis showed that the effect of the sea-salt aerosol size is directly related to the slope of the linear fit of the $N_{r}-W$ relationship at cloud base. A negative slope $\left(N_{r}\right.$ decreasing with increasing $\left.W\right)$ points to the predominance of small sea-salt nuclei, in which stronger updrafts nucleate a greater number of smaller cloud drops with smaller coalescence efficiencies, resulting in fewer embryonic rain drops. A positive slope $\left(N_{r}\right.$ increasing with increasing $W$ ), on the other hand, indicates the presence of large sea-salt nuclei. These large sea-salt particles are the source of large cloud drops, which grow to embryonic rain drops by condensation and coalescence. These results, thus, suggest that the $N_{r}-W$ relationship may serve as an indicator of the effectiveness of large sea-salt aerosol. 

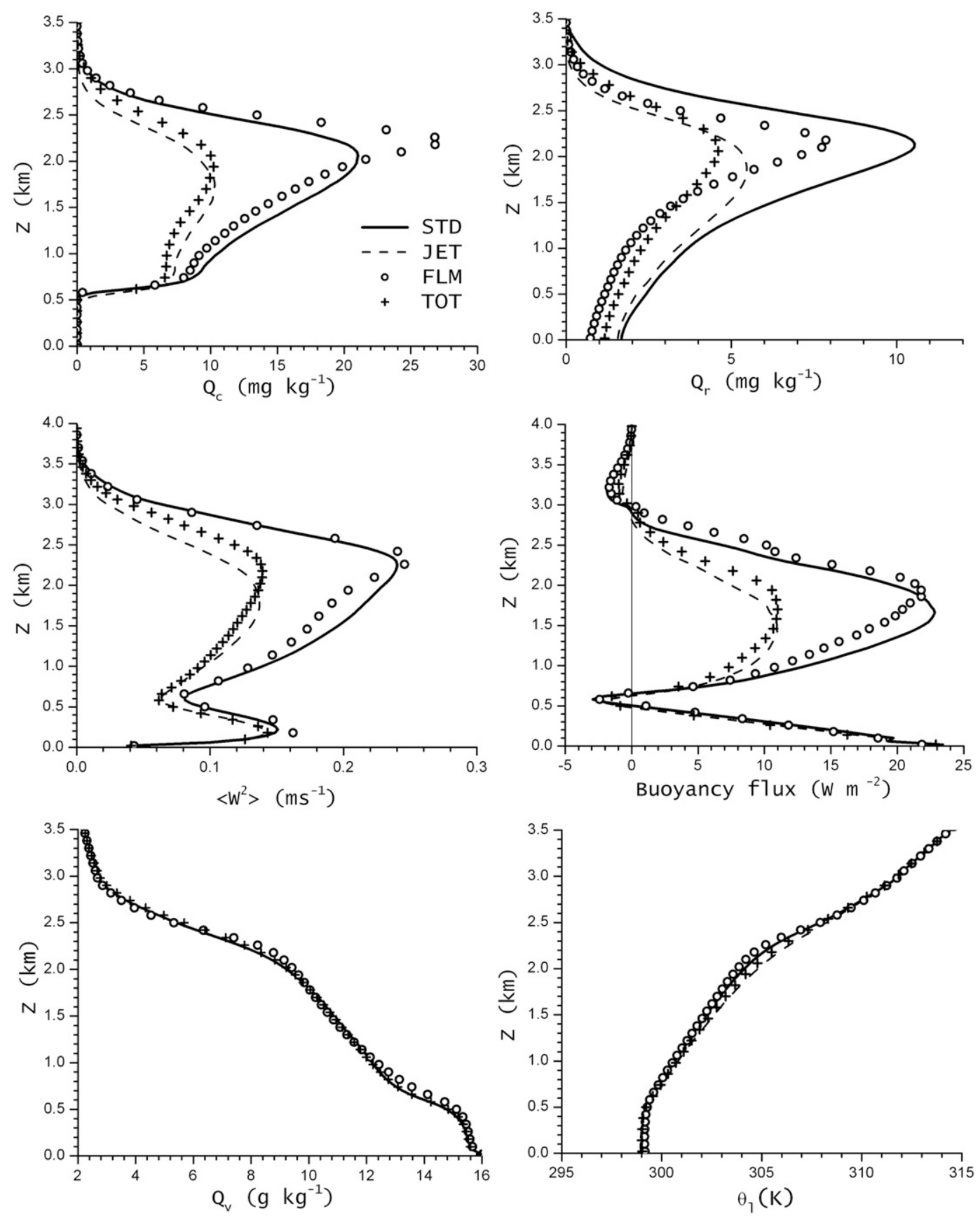

FIG. 14. Profiles for the four simulations of cloud and rainwater: (top) (left) $Q_{c}$ and (right) $Q_{r}$; (middle) (left) vertical velocity variance and (right) buoyancy flux; and (bottom) (left) water vapor $Q_{v}$ and (right) liquid water potential temperature $\theta_{l}$. All averaged over the last $4 \mathrm{~h}$ of simulation and the whole integration domain.

The small and large sea-salt aerosols are often associated with film and jet aerosol modes of the sea spray produced by surface winds. According to O'Dowd et al. (1997) the concentration of the two modes varies nonlinearly with wind speed, and increasing the wind speed from 12 to $17 \mathrm{~m} \mathrm{~s}^{-1}$ results in a tripling of the film aerosol concentration but only a $40 \%$ increase in jet aerosol. The much larger increase in film-size aerosol load with wind speed suggests that suppression of precipitation by these aerosols might play a role at high wind speeds. However, we find that the accumulated precipitation in TOT17 $\left(17 \mathrm{~m} \mathrm{~s}^{-1}\right)$ is greater than in TOT $\left(12 \mathrm{~m} \mathrm{~s}^{-1}\right)$, revealing that the drizzle embryos arising from the jet nuclei dominate the precipitation 
process over the increase in $\mathrm{CCN}$ from the film-size particles.

We also found that the precipitation process depends not only on the surface sea-salt source characteristics, but on the background CCN spectrum as well. The same TOT and TOT17 surface sea-salt spectra specified in an environment with a higher aerosol load resulted in a decreased accumulated precipitation when the surface wind increased.

Although useful as an indicator of the possible role of sea-salt aerosols, the $N_{r}-W$ relationship at cloud base, however, is not capable of predicting precipitation rate or the dynamical feedbacks of precipitation on the boundary layer cloud and thermodynamic fields. As our analysis shows, most of the precipitation is associated with downdrafts, which are spatially separate from the cloud-base updraft regions where droplets are nucleated. Furthermore, although the drizzle embryos created in the vicinity of cloud base are one mechanism for initiating the precipitation process, other factors such as cloud liquid water content dictate the ultimate magnitude of precipitation (Stevens and Seifert 2008; Nuijens et al. 2009). Many other dynamical factors may be relevant to precipitation as well. For instance, Cheng et al. (2009) found that environments with a higher background aerosol load may promote increased evaporation and a reduction in cloud cover. Clearly, the manner in which seasalt aerosol influences the precipitation process is a complicated interplay among dynamical factors such as entrainments, vertical velocity, and its effect on supersaturation, and the microphysical parameters associated with the drop size distribution.

Our simulations indirectly provide new insight into the nucleation parameterization problem. Parameterizations of cloud droplet nucleation have been constructed using various degrees of sophistication. Fundamentally, they subject an aerosol spectrum to a given updraft and provide a resulting spectrum (or simply a concentration) of nucleated cloud droplets. Deeper in the cloud, the autoconversion process converts some of these cloud droplets into precipitation, which can then collect additional cloud droplets via accretion. The relationship between embryonic precipitation drops and vertical velocity explored in this paper suggests that many precipitation drops are rooted near cloud base and are created along with cloud droplets. These results suggest that nucleation of precipitation-size droplets occurs in these regions, in addition to the typical cloud droplet nucleation process, and that representing these effects in bulk microphysical parameterizations may be important. Furthermore, the simulations confirm that gridmean supersaturation (even conditionally calculated only over regions of positive supersaturation) is insufficient for calculating the concentration of nucleated cloud droplets. Instead, an accurate grid-mean droplet concentration can be calculated only by knowing the PDF of supersaturation.

The size-resolving microphysics in the LES accounts for coalescence processing of aerosol, in which precipitation growth is associated with reduced cloud droplet concentrations. Upon evaporation, these smaller droplet concentrations are reflected as reduced $\mathrm{CCN}$ concentrations and a movement of the $\mathrm{CCN}$ size distribution toward larger sizes. However, the lack of a background $\mathrm{CCN}$ source apart from the surface sea-salt flux is one notable limitation of this experimental framework and precludes longer time integrations. Our simulations did not consider the much larger aerosols with dry radii $>$ $10 \mu \mathrm{m}$ (referred to as spume or supergiant aerosols) for two reasons: 1) they have concentrations an order of magnitude smaller than jet aerosols but essentially will form rain embryos in the same size range, and 2) because of their large size they have large sedimentation velocities and only a very lucky few will be present in cloud-base updrafts. Nevertheless, even this small number of supergiant aerosols brought into cloud by strong updrafts may even further increase the effect of giant sea-salt aerosol particles on rainfall formation.

Among other limitations is the rather marginal size of the integration domain in our simulations. As the study by Feingold et al. (2010) has shown, larger domains are necessary to adequately represent mesoscale variability in the form of precipitation-driven outflows initiating new cells. This limitation becomes problematic for longerterm simulations. Larger domains and longer simulations would incorporate aerosol sources, multiday advective forcings, and subsidence divergence and would shed light on the feedbacks among precipitation rate, entrainment, and boundary layer budgets of heat, moisture, and momentum.

Our study focused only on the microphysical aspects of the changes in surface winds, and for the sake of simplicity we deliberately neglected the dynamical effects of surface wind speed differences (e.g., changes in surface fluxes of heat, moisture, and momentum) on the simulated cloud system. This manner of experimental design although yielding a bit of realism gains much more by way of enabling a clearer interpretation of simulation results in the ability to single out the effects of aerosol changes alone. Future research efforts will consider the combined effects of surface winds on aerosol properties and on cloud dynamics in the form of a more complete factorialanalysis approach. These dynamical effects of surface winds should include not only change in surface fluxes but also may be accompanied by changes in other large-scale parameters such as thermodynamic properties, subsidence rate, and wind shear. 
Acknowledgments. We thank an anonymous reviewer for very constructive comments. This investigation was supported by NOAA/Office of Oceanic and Atmospheric Research under NOAA-University of Oklahoma Cooperative Agreements NA17RJ1227 and NA08OAR4320904, the U.S. Department of Commerce, by the ONR Grants N00014-08-10681 and N00014-1110439, and by the Office of Science (BER), U.S. Department of Energy, Grant DE-FG02-05ER64062, as part of the Atmospheric Radiation Measurement Program, U.S. Department of Energy. Mechem was supported by U.S. National Oceanic and Atmospheric Administration (NOAA) Climate Program Office (CPO) Grant NA10OAR4310160, ONR Grant N00014-1110518, the University of Kansas General Research Fund allocation 230211, and New Faculty Startup funds. The computing for this project was performed at the OU Supercomputing Center for Education and Research (OSCER) at the University of Oklahoma.

\section{APPENDIX}

\section{Sensitivity to the Choice of Constant $k$ and Concentration of Large Nuclei}

To test the sensitivity to the choice of a particular value of the constant $k$, which represents a constant of proportionality between the aerosol dry radius and the deliquesced ("wet") radius of the aerosol as it enters cloud base from the subcloud layer, we assume that air parcels rise from the surface in updrafts of $1.0 \mathrm{~m} \mathrm{~s}^{-1}$, much stronger than the updraft range of $0.2-0.4 \mathrm{~m} \mathrm{~s}^{-1}$ present in our simulations. In such a case, an approach similar to that of Ivanova et al. (1977) would yield a value of $k \sim 4$, smaller than the value of 6 we employed.

The negative slope $d \log n / d \log r$ of a typical sea-salt distribution (with $n$ representing the concentration) according to Fig. 22 in Lewis and Schwartz (2004) varies in the range about 2.5-3.0. Rescaling of the "dry" radius range by a multiplier $4 / 6$ (ratio of two different values of $k$ ) results in rescaling of the $\log N$ by a factor of $(2.5-$ $3.0) \times \log (2 / 3)=(0.44-0.53)$, or decrease in the concentration of $N$ by a factor of (2.75-3.4). In other words, reducing $k$ from 6 to 4 is equivalent to a reduction in seasalt aerosols by a factor of (2.75-3.4). We conducted a simulation (LN5) that decreased the concentration of sea-salt aerosol by a factor of 5 . This simulation serves as a limiting case to indirectly address model sensitivity to $k$.

The sensitivity experiment LN5 was specified based on benchmark experiment TOT that simulated RICO conditions under surface winds of $12 \mathrm{~m} \mathrm{~s}^{-1}$ with the total background concentration of $104.4 \mathrm{~cm}^{-3}$. The concentration of sea-salt nuclei was decreased from $29.27 \mathrm{~cm}^{-3}$

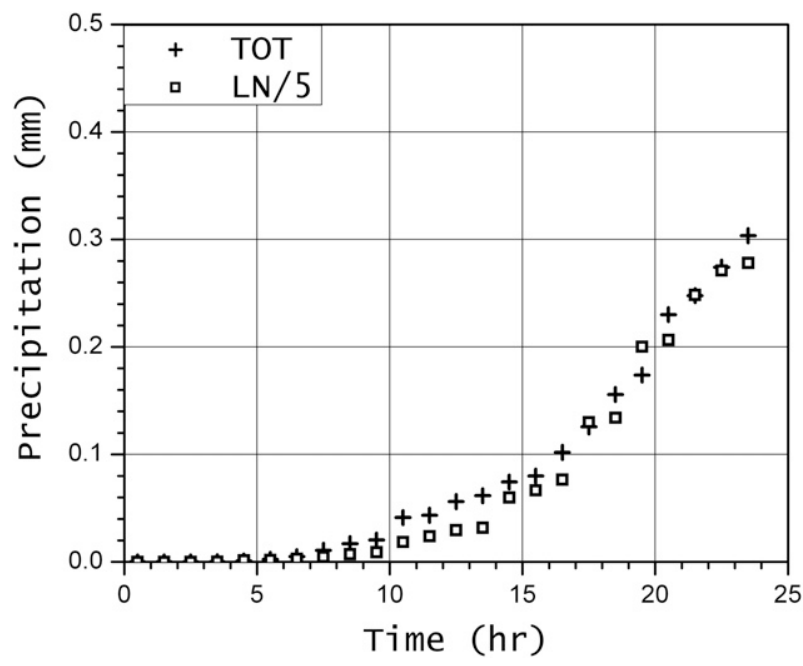

FIG. A1. Evolution of the accumulated surface precipitation for the TOT and LN5 simulations.

in TOT to $24.514 \mathrm{~cm}^{-3}$ in LN5 (Table 1). The concentration of the largest aerosols (bins 15-19; Table 2) was decreased by a factor of 5 , from 2.07 to $0.414 \mathrm{~cm}^{-3}$. For a smooth transition in the CCN distribution function, the concentration in bin 14 was decreased by a factor of 2 from 6.2 to $3.1 \mathrm{~cm}^{-3}$.

The accumulated surface precipitation for both the LN5 and TOT simulations is shown in Fig. A1. After initial $5 \mathrm{~h}$ spinup time, small amounts of drizzle start forming in both experiments. At $t=14 \mathrm{~h}$ the difference is the largest $(0.066 \mathrm{~mm}$ in TOT versus $0.048 \mathrm{~mm}$ in LN5, a decrease of $\sim 27 \%$ ). Obviously the larger number of rain drop embryos formed on large $\mathrm{CCN}$ in the TOT experiment grow via accretion of cloud droplets and are responsible for this initial surface precipitation. However, as the simulation progresses, autoconversion dominates production of rain drops, as was shown also in Fig. 7, and the accumulated precipitation in the LN5 quickly catches up and matches that of the TOT experiment. The LN5 test confirms that the cumulative precipitation at the end of the simulation is rather insensitive to the exact specification of the wet radii for large nuclei, although the latter may influence the rather weak precipitation rates in small cumuli formed at the initial stage of the simulations.

\section{REFERENCES}

Abdul-Razzak, H., S. J. Ghan, and C. Rivera-Carpio, 1998: A parameterization of aerosol activation. 1. Single aerosol type. J. Geophys. Res., 103, 6123-6131.

Betts, A. K., 1997: Trade cumulus: Observations and modeling. The Physics and Parameterization of Moist Atmospheric Convection, R. K. Smith, Ed., Kluwer Academic, 99-126. 
Blyth, A. M., S. G. Lasher-Trapp, W. A. Cooper, C. A. Knight, and J. Latham, 2003: The role of giant and ultragiant nuclei in the formation of early radar echoes in warm cumulus clouds. J. Atmos. Sci., 60, 2557-2572.

Bony, S., and J.-L. Dufresne, 2005: Marine boundary layer clouds at the heart of tropical cloud feedback uncertainties in climate models. Geophys. Res. Lett., 32, L20806, doi:10.1029/2005GL023851.

Cheng, W. Y. Y., G. G. Carrió, W. R. Cotton, and S. M. Saleeby, 2009: Influence of cloud condensation and giant cloud condensation nuclei on the development of precipitating trade wind cumuli in a large eddy simulation. J. Geophys. Res., 114, D08201, doi:10.1029/2008JD011011.

Cohard, J.-M., J.-P. Pinty, and C. Bedos, 1998: Extending Twomey's analytical estimate of nucleated cloud droplet concentrations from CCN spectra. J. Atmos. Sci., 55, 3348-3357.

Cólon-Robles, Marilé, R. M. Rauber, and J. B. Jensen, 2006: Influence of low-level wind speed on droplet spectra near cloud base in trade wind cumulus. Geophys. Res. Lett., 33, L20814, doi:10.1029/2006GL027487.

Cooper, W. A., R. T. Bruintjes, and G. K. Mather, 1997: Calculations pertaining to hygroscopic seeding with flares. J. Appl. Meteor., 36, 1449-1469.

Dearden, C., 2009: Investigating the simulation of cloud microphysical processes in numerical model using a one-dimensional dynamical framework. Atmos. Sci. Lett., 10, 207-214.

Deardorff, J. W., 1980: Stratocumulus-capped mixed layers derived from a three-dimensional model. Bound.-Layer Meteor., 18, 495-527.

Feingold, G., W. R. Cotton, S. M. Kreidenweis, and J. T. Davis, 1999: The impact of giant cloud condensation nuclei on drizzle formation in stratocumulus: Implications for cloud radiative properties. J. Atmos. Sci., 56, 4100-4117.

—- I. Koren, H. Wang, H. Xue, and W. A. Brewer, 2010: Precipitation-generated oscillations in open cellular cloud fields. Nature, 466, 849-852, doi:10.1038/nature09314.

Gerber, H. E., G. M. Frick, J. B. Jensen, and J. G. Hudson, 2008: Entrainment, mixing, and microphysics in trade-wind cumulus. J. Meteor. Soc. Japan, 86A, 87-106.

Ghan, S. J., G. Guzman, and H. Abdul-Razzak, 1998: Competition between sea salt and sulfate particles as cloud condensation nuclei. J. Atmos. Sci., 55, 3340-3347.

Göke, S., H. T. Ochs III, and R. M. Rauber, 2007: Radar analysis of precipitation initiation in maritime versus continental clouds near the Florida coast: Inferences concerning the role of $\mathrm{CCN}$ and giant nuclei. J. Atmos. Sci., 64, 3695-3707.

Hudson, J. G., and S. S. Yum, 2001: Maritime-continental drizzle contrasts in small cumuli. J. Atmos. Sci., 58, 915-926.

, and S. Mishra, 2007: Relationships between CCN and cloud microphysics variations in clean maritime air. Geophys. Res. Lett., 34, L16804, doi:10.1029/2007GL030044.

_, S. Noble, V. Jha, and S. Mishra, 2009: Correlations of small cumuli droplet and drizzle drop concentrations with cloud condensation nuclei concentrations. J. Geophys. Res., 114, D05201, doi:10.1029/2008JD010581.

Illingworth, A. J., 1988: The formation of rain in convective clouds. Nature, 336, 754-756.

Ivanova, E. T., Y. L. Kogan, I. P. Mazin, and M. S. Permyakov, 1977: Method of parameterizing the condensation process of droplet growth in numerical models. Izv. Acad. Sci. USSR, Atmos. Oceanic Phys., 13, 821-826.

Jiang, H., G. Feingold, and I. Koren, 2009: Effect of aerosol on trade cumulus cloud morphology. J. Geophys. Res., 114, D11209, doi:10.1029/2009JD011750.
Johnson, D. B., 1982: The role of giant and ultragiant aerosol particles in warm rain initiation. J. Atmos. Sci., 39, 448-460.

Khairoutdinov, M. F., and Y. L. Kogan, 1999: A large eddy simulation model with explicit microphysics: Validation against aircraft observations of a stratocumulus-topped boundary layer. J. Atmos. Sci., 56, 2115-2131.

—, and D. A. Randall, 2003: Cloud resolving modeling of the ARM summer 1997 IOP: Model formulation, results, uncertainties, and sensitivities. J. Atmos. Sci., 60, 607-625.

Knight, C. A., L. J. Miller, and R. A. Rilling, 2008: Aspects of precipitation development in trade wind cumulus revealed by differential reflectivity at S band. J. Atmos. Sci., 65, 2563 2580.

Kogan, Y. L., 1991: The simulation of a convective cloud in a 3D model with explicit microphysics. Part I: Model description and sensitivity experiments. J. Atmos. Sci., 48, 1160-1189.

_ 2006: Large eddy simulation of air parcels in stratocumulus clouds: Time scales and spatial variability. J. Atmos. Sci., 63, 952-967.

— D. K. Lilly, Z. N. Kogan, and V. V. Filyushkin, 1994: The effect of CCN regeneration on the evolution of stratocumulus cloud layers. Atmos. Res., 33, 137-150.

—, M. P. Khairoutdinov, D. K. Lilly, Z. N. Kogan, and Q. Liu, 1995: Modeling of stratocumulus cloud layers in a large eddy simulation model with explicit microphysics. J. Atmos. Sci., 52, 2923-2940.

Laird, N. F., H. T. Ochs III, R. M. Rauber, and L. J. Miller, 2000: Initial precipitation formation in warm Florida cumulus J. Atmos. Sci., 57, 3740-3751.

Lasher-Trapp, S. G., C. A. Knight, and J. M. Straka, 2001: Early radar echoes from ultragiant aerosol in a cumulus congestus: Modeling and observations. J. Atmos. Sci., 58, 3545-3561.

Lewis, E. R., and S. E. Schwartz, 2004: Sea Salt Aerosol Production: Mechanisms, Methods, Measurements, and Models-A Critical Review. Geophys. Monogr., Vol. 152, Amer. Geophys. Union, $413 \mathrm{pp}$.

Lowenstein, J. H., A. M. Blyth, and R. P. Lawson, 2010: Early evolution of the largest-sized droplets in maritime cumulus clouds. Quart. J. Roy. Meteor. Soc., 136, 708-717.

Medeiros, B., B. Stevens, I. M. Held, M. Zhao, D. L. Williamson, J. G. Olson, and C. S. Bretherton, 2008: Aquaplanets, climate sensitivity, and low clouds. J. Climate, 21, 4974-4991.

Nuijens, L., B. Stevens, and A. P. Siebesma, 2009: The environment of precipitating shallow cumulus convection. J. Atmos. Sci., 66, 1962-1979.

O'Dowd, C. D., M. H. Smith, I. E. Consterdine, and J. A. Lowe, 1997: Marine aerosol, sea-salt, and the marine sulphur cycle: A short review. Atmos. Environ., 31, 73-80.

Rauber, R. M., and Coauthors, 2007: Rain in shallow cumulus over the ocean: The RICO campaign. Bull. Amer. Meteor. Soc., 88, 1912-1928.

Reiche, C. H., and S. Lasher-Trapp, 2010: The minor importance of giant aerosol to precipitation development within small trade wind cumuli observed during RICO. Atmos. Res., 95, 386-399.

Riehl, H., C. Yeh, J. S. Malkus, and N. E. LaSeur, 1951: The northeast trade of the Pacific Ocean. Quart. J. Roy. Meteor. Soc., 77, 598-626.

Schumacher, C., and R. A. Houze Jr., 2003: The TRMM precipitation radar's view of shallow, isolated rain. J. Appl. Meteor., $\mathbf{4 2}$, $1519-1524$.

Short, D. A., and K. Nakamura, 2000: TRMM radar observations of shallow precipitation over the tropical oceans. J. Climate, 13, 4107-4124. 
Siebesma, A. P., 1998: Shallow cumulus convection. Buoyant Convection in Geophysical Flows, E. J. Plate et al., Eds., Kluwer Academic, 441-486.

Smolarkiewicz, P. K., and W. W. Grabowski, 1990: The multidimensional positive definite advection transport algorithm: Non-oscillatory option. J. Comput. Phys., 86, 355-375.

Snider, J. R., S. Guibert, J.-L. Brenguier, and J.-P. Putaud, 2003: Aerosol activation in marine stratocumulus clouds: 2. Köhler and parcel theory closure studies. J. Geophys. Res., 108, 8629, doi:10.1029/2002JD002692.

Snodgrass, E. R., L. Di Girolamo, and R. M. Rauber, 2009: Precipitation characteristics of trade wind clouds during RICO derived from radar, satellite, and aircraft measurements. J. Appl. Meteor. Climatol., 48, 464-483.

Stein, U., and P. Alpert, 1993: Factor separation in numerical simulations. J. Atmos. Sci., 50, 2107-2115.

Stevens, B., 2005: Atmospheric moist convection. Annu. Rev. Earth Planet. Sci., 33, 605-643.

— , and A. Seifert, 2008: Understanding macrophysical outcomes of microphysical choices in simulations of shallow cumulus convection. J. Meteor. Soc. Japan, 86A, 143-162.
— , and G. Feingold, 2009: Untangling aerosol effects on clouds and precipitation in a buffered system. Nature, 461, 607-613, doi:10.1038/nature08281.

Twomey, S., 1959: The nuclei of natural cloud formation. Part II: The supersaturation in natural clouds and the variation of cloud droplet concentration. Pure Appl. Geophys., 43, $243-$ 249.

van Zanten, M. C., and Coauthors, 2011: Controls on precipitation and cloudiness in simulations of trade-wind cumulus as observed during RICO. J. Adv. Model. Earth Syst., 3, M06001, doi:10.1029/2011MS000056.

Wyant, M. C., C. S. Bretherton, J. T. Bacmeister, J. T. Kiehl, I. M. Held, M. Zhao, S. A. Klein, and B. A. Soden, 2006: A comparison of low-latitude cloud properties and their response to climate change in three AGCMs sorted into regimes using mid-tropospheric vertical velocity. Climate Dyn., 27, 261-279.

Zhao, G., and L. Di Girolamo, 2007: Statistics on the macrophysical properties of trade wind cumuli over the tropical western Atlantic. J. Geophys. Res., 112, D10204, doi:10.1029/ 2006JD007371. 